NASA/TM-1998-112217

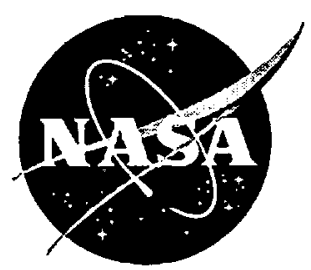

\title{
Aiding Vertical Guidance Understanding
}

Michael Feary, San Jose State University, San Jose, California

Daniel McCrobie, Honeywell Inc., Phoenix, Arizona

Martin Alkin, Federal Express Inc., Memphis, Tennessee

Lance Sherry, Honeywell Inc., Phoenix, Arizona

Peter Polson, University of Colorado, Boulder, Colorado

Everett Palmer, Ames Research Center, Moffett Field, California

Noreen McQuinn, Boeing-Douglas Products Division, Long Beach, California

National Aeronautics and

Space Administration

Ames Research Center

Moffett Field, California 93035-1000 


\section{Acknowledgments}

Thanks to the following people for their help in performing this study. Joe Jackson (Honeywell) for advice and management support.

Pankaj Godiwala (Honeywell) for help with the FMS and programming support.

Kevin Jordan (San Jose State University) for advice and guidance.

Joseph Cicinelli (Honeywell) for help in running the study.

Bob Geiger (Boeing) for simulator support and flexibility in scheduling.

Mark Willburger (Boeing) for help in running the study and rewiring the FTD.

Captain Ed Gorman (Honeywell) for initial review of the training and scenario.

Gary Bisgaard (Honeywell) for reprogramming and testing the DEU.

Captain James Ward (FedEx) for support with pilots and resources.

Captain Warren Travis (FedEx) for support with training materials and pilots.

Captain Rudolf Bornhauser (Swissair) for cooperation with pilots.

Captain Mike Padron (FedEx) for support and review of the tutor.

Available from:

NASA Center for AeroSpace Information

800 Elkridge Landing Road

Linthicum Heights, MD 21090-2934

Pricc Code: A 17
National Technical Information Service 5285 Port Royal Road Springfield, VA 22161

Price Code: A10 


\section{CONTENTS}

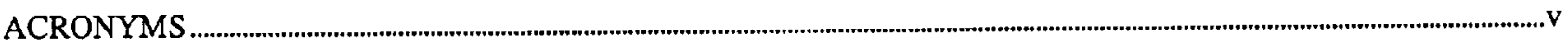

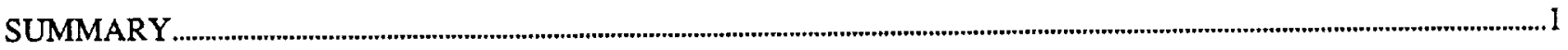

INTRODUCTION

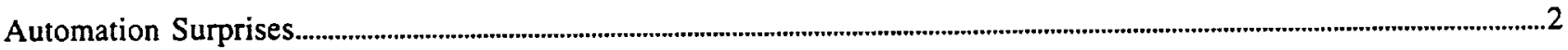

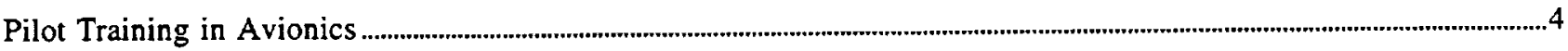

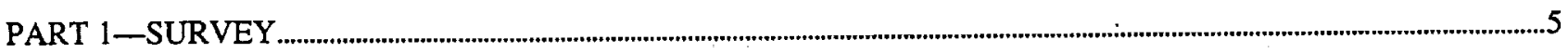

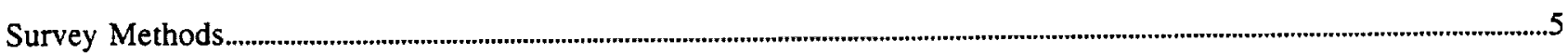

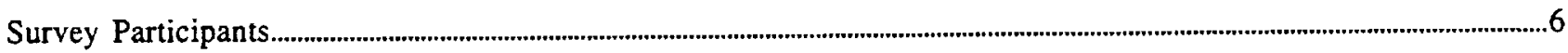

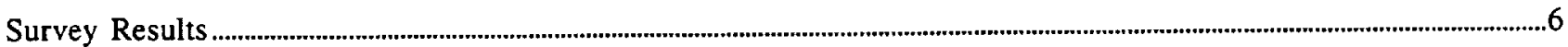

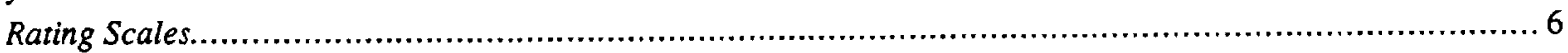

Open-Ended Comments........................................................................................... 7

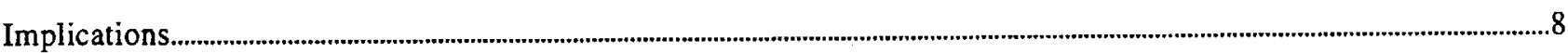

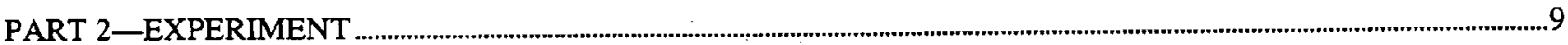

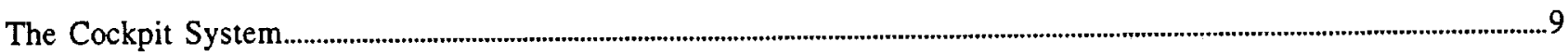

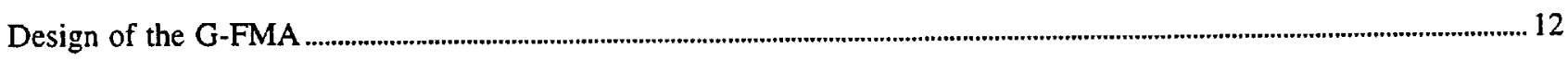

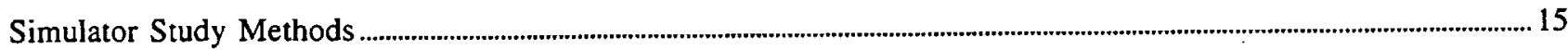

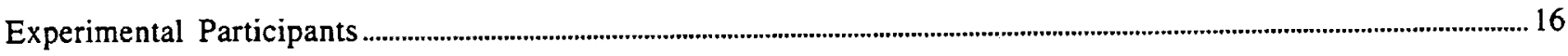

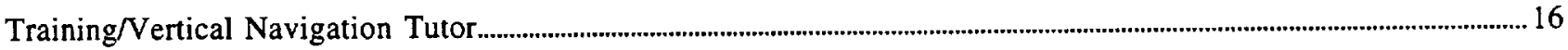

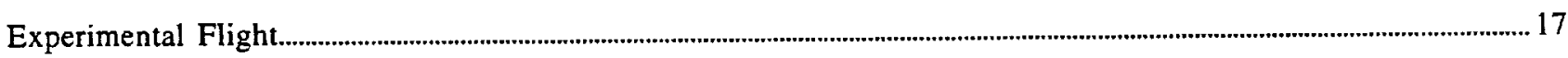

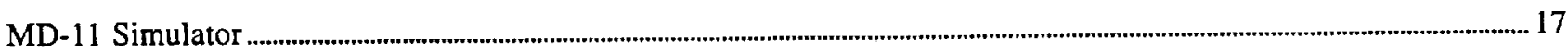

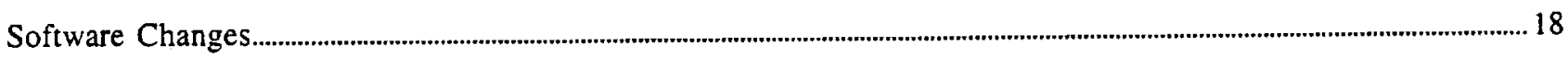

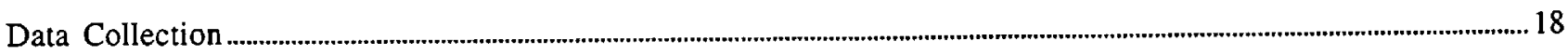

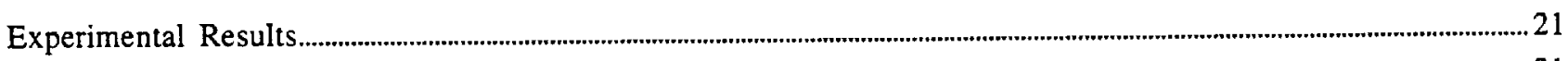

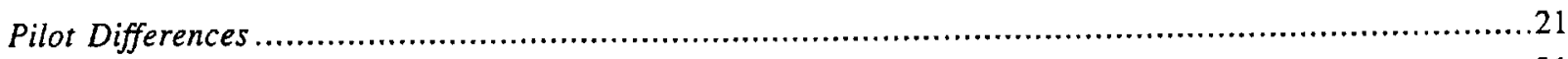

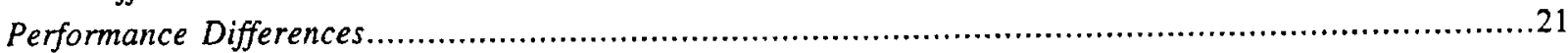

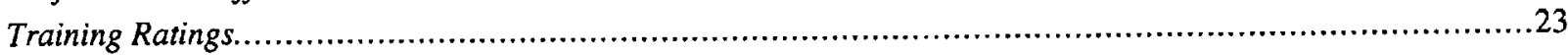

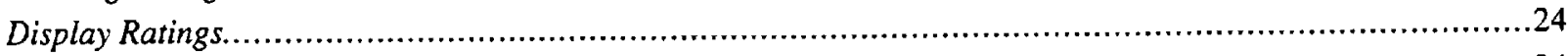

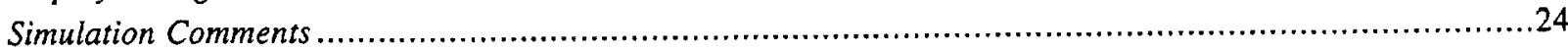

DISCUSSION OF EXPERIMENTAL RESULTS ......................................................................................................................2

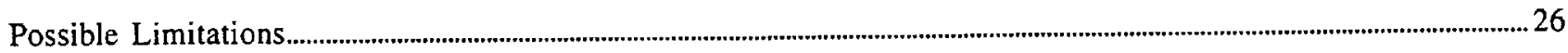

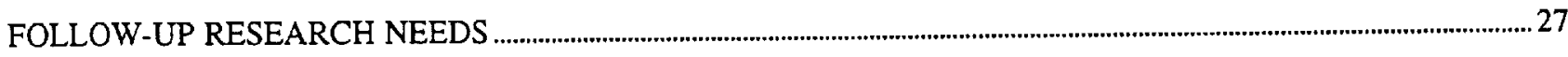

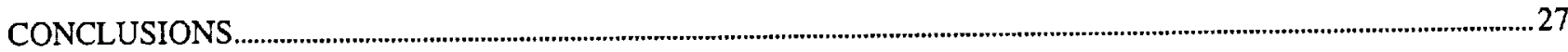


APPENDIX A-QUESTIONNAIRE

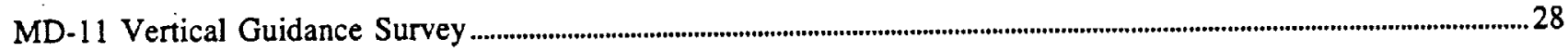

APPENDIX B-RESPONSES FROM THE QUESTIONNAIRE

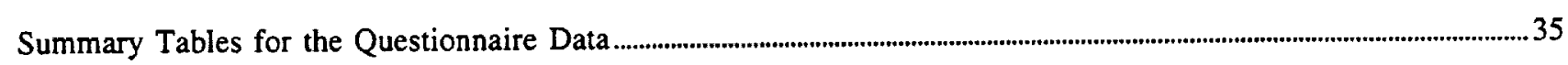

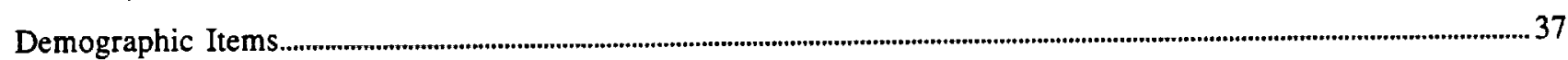

Use of the MD-11 Automation

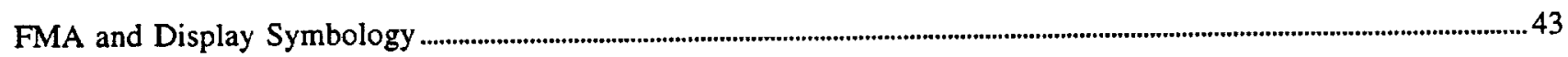

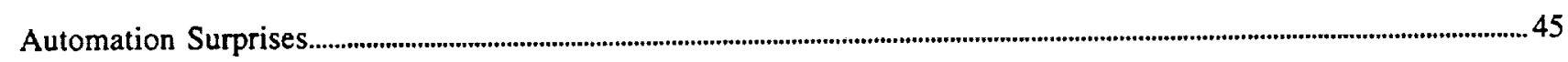

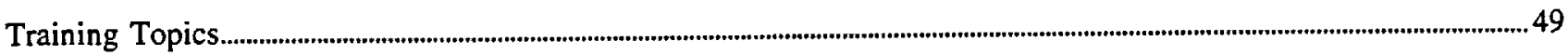

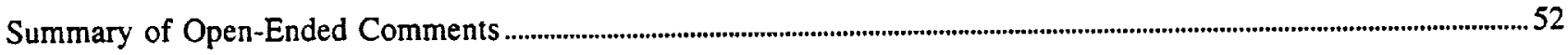

APPENDIX C_EXAMPLE OF THE TUTOR USED IN THE EXPERIMENT

APPENDIX D-EXPERMMENTAL PROCEDURE AND SIMULATED FLIGHT.................................................................60

APPENDIX E-ANALYSIS OF VARIANCE (ANOVA) FOR EACH QUESTION ASKED DURING

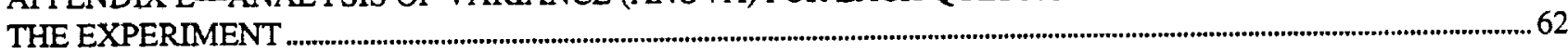

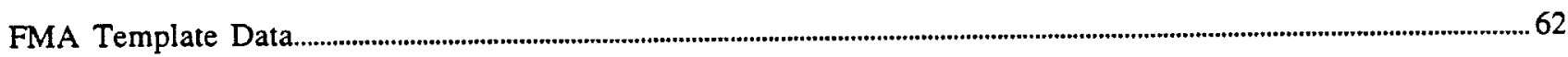

APPENDIX F_-RESULTS FROM THE SIMULATION EXPERIMENT ..............................................................................69

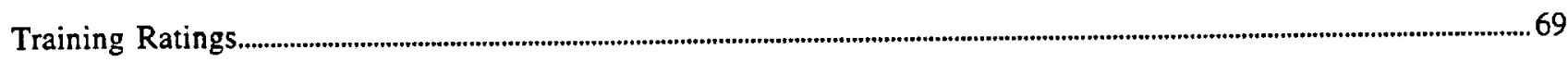

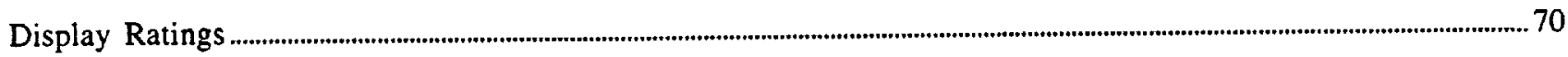

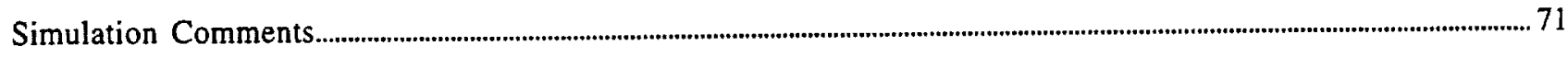

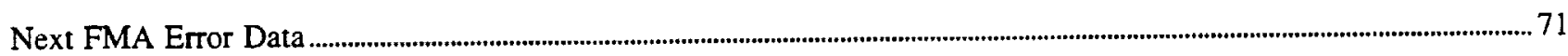

APPENDIX G_DESCRIPTION OF THE INTENTIONAL FMA

REFERENCES 


\section{ACRONYMS}

$\begin{array}{ll}\text { ANOVA } & \text { analysis of variance } \\ \text { ASRS } & \text { Aviation Safety Reporting System } \\ \text { ATC } & \text { air traffic control } \\ \text { CLB } & \text { climb } \\ \text { DEU } & \text { display electronics unit } \\ \text { EAD } & \text { equipment acquisition document } \\ \text { FMA } & \text { flight mode annunciator } \\ \text { FMC } & \text { flight management computer } \\ \text { FMS } & \text { Flight Management System } \\ \text { FPA } & \text { flight path angle } \\ \text { GCP } & \text { glareshield control panel } \\ \text { G-FMA } & \text { Guidance-Flight Management System } \\ \text { MCDU } & \text { multifunction control and display unit } \\ \text { MCT } & \text { maximum continuous thrust } \\ \text { ND } & \text { navigation display } \\ \text { PFD } & \text { primary flight display } \\ \text { PROF } & \text { an abbreviation for profile mode } \\ \text { SAGAT } & \text { situation awareness global assessment technique } \\ \text { T/O } & \text { takeoff } \\ \text { V/S } & \text { vertical speed } \\ \text { VNAV } & \text { vertical navigation } \\ \text { VSD } & \text { vertical situation display } \\ \end{array}$





\title{
AIDING VERTICAL GUIDANCE UNDERSTANDING
}

\author{
Michael Feary, ${ }^{*}$ Daniel McCrobie, ${ }^{\dagger}$ Martin Alkin, ${ }^{\ddagger}$ Lance Sherry, ${ }^{\dagger}$ \\ Peter Polson, ${ }^{8}$ Everett Palmer, and Noreen McQuinn ${ }^{\mathbf{I}}$
}

Ames Research Center

\section{SUMMARY}

A two-part study was conducted to evaluate modern flight deck automation and interfaces. In the first part, a survey was performed to validate the existence of automation surprises with current pilots. Results indicated that pilots were often surprised by the behavior of the automation. There were several surprises that were reported more frequently than others. An experimental study was then performed to evaluate (1) the reduction of automation surprises through training specifically for the vertical guidance logic, and (2) a new display that describes the flight guidance in terms of aircraft behaviors instead of control modes. The study was performed in a simulator that was used to run a complete flight with actual airline pilots. Three groups were used to evaluate the guidance display and training. In the training condition, participants went through a training program for vertical guidance before flying the simulation. In the display condition, participants ran through the same training program and then flew the experimental scenario with the new Guidance-Flight Mode Annunciator (G-FMA). Results showed improved pilot performance when given training specifically for the vertical guidance logic and greater improvements when given the training and the new G-FMA. Using actual behavior of the avionics to design pilot training and FMA is feasible, and when the automated vertical guidance mode of the Flight Management System is engaged, the display of the guidance mode and targets yields improved pilot performance.

\section{INTRODUCTION}

In flight systems design, the introduction of automation has increased efficiency, precision, and safety. At the same time that avionics efficiency has increased, a new category of incidents has been introduced to aviation. These incidents may result from a mismatch between the actual behavior of the avionics and the pilot's expectations of the avionics. Under some conditions, the flight crew may have difficulty recognizing what the avionics are doing and even more difficulty predicting what will

\footnotetext{
'San Jose State University, San Jose, California.

${ }^{\dagger}$ Honeywell Inc., Phoenix, Arizona.

${ }^{*}$ Federal Express Inc., Memphis, Tennessee.

${ }^{\circledR}$ University of Colorado, Boulder, Colorado.

Boeing-Douglas Products Division, Long Beach, California.
} 
happen next. The inability to predict what the automation will do next is a condition for an automation surprise.

This paper will briefly review automation surprises in aviation and will present a model of cockpit operations. This model will form the foundation for designing new training and annunciations for the vertical guidance system in jet aircraft. It has been shown that automation surprises occur when the pilot's understanding of the avionics is not complete. The underlying premise of this research is to design cockpit displays and pilot training based on an exact description of the avionics software.

We will first discuss automation surprises and pilot training issues and then describe the survey methods and results. The survey gave us insight into some of the problem areas that were underlying automation surprises. The next step was to devise an experiment to test a new display and training based on the behavior of the avionics software and to verify that this has an effect on pilot understanding of the avionics system. We will then describe the Cockpit System Model of the airplane, how we implemented the new mode annunciation scheme, and details of the experiment. Experimental results and follow-up research needs will then be discussed.

\section{Automation Surprises}

Palmer (1995) describes automation surprises as occurrences when the automation behaves in a manner that is different from what the pilot expects. The automation behaves as it was designed and programmed, but it is sometimes inconsistent with the pilot's expectations.

Vakil et al. (1995b) performed a study of mode awareness problems described in pilot reports to the Aviation Safety Reporting System (ASRS) submitted during the years 1990 to 1994. They found 184 reports in which the crew experienced an automation surprise that Vakil et al. (1995a) attributed to the understanding of modes on the airplane. Thirty-four percent of the incidents described a failure, such as a disparity within the data base or a hardware failure. The remaining categories of surprises were attributed to insufficient knowledge of the avionics (18\%), pilot mistakes during data entry of the Flight Management System (FMS) flight plan through the multifunction control and display unit (MCDU) (46\%), failure to detect or anticipate a mode transition (20\%), and coordination problems between crew members (14\%). The percentages add up to more than $100 \%$ because approximately $30 \%$ of the incidents were classified in more than one category.

Subtle changes in modes are one of the conditions that may lead to automation surprises (Wiener, 1989). These can occur when the pilot believes that one mode of operation is current when actually another mode is active. Entering commands for an assumed mode may be inappropriate for the mode in force. At this point, the behavior of the aircraft is the source of feedback and it is inconsistent with expectations. When this happens, pilots ask "What is it doing now?" or "What is it going to do next?" This, and other side effects of automation surprises, may lead pilots to mistrust the automatic systems.

In some incidents involving automation surprises, pilots report that they discover the error by observing basic aircraft displays, such as the altimeter and the vertical speed indicator (Woods et al., 1994). In these cases, crews were aware of what the aircraft was doing, but they were not aware of the state of the automation. 
Palmer (1995) provides an example of a mode error that occurs when the same pilot action results in different behaviors depending on the mode engaged. During a climb with altitude capture engaged, the pilot can freely change the pitch autopilot modes. Changing the pitch mode does not affect the altitude capture and it will remain armed, causing the airplane to level off at the set altitude. If the avionics should switch into another mode, then the airplane will not level off at the target altitude but at the altitude programmed into the flight management computer (FMC). Here, subtle differences in modes and silent transitions between modes have large effects on how the airplane behaves during a flight.

Some of the conditions that have been reported to lead to poor understanding in the cockpit are described below. These are not listed in a particular order, but are meant to focus on some of the problems that are inherent with highly complex, automated avionics.

- Two crew members input data to one system. This can be confusing if there is a lack of crew coordination. If one pilot enters data, this may change the way the airplane behaves; the other pilot must be aware of changes and their underlying consequences to avert an automation surprise. A series of checks between pilots will minimize this coordination problem.

- Misinterpretation of warnings. In his paper on automation surprises, Palmer (1995) shows that one occurred because a pilot interpreted a waming as a malfunction rather than as an advisory of an impending maneuver that would exceed established parameters. Different behaviors are needed to deal with the different problems.

- Automation can add complexity to the task. In their summary of aviation incidents, Funk et al. (1995) reported that many incidents pointed to perceived overcomplexity of the avionics (5\% of reports) and the fact that the automation may fail to perform to the pilot's expectations (5\%).

- Pilots may rely too heavily on automation. Nearly $7 \%$ of the reports in the study done by Funk et al. (1995) stated that pilots may place too much confidence in the automation. This can lead to complacent pilots who are not aware of system changes as they are happening. Another problem noted is that automation may not help pilots out of a situation. If any performance limits of the airplane are exceeded (such as an extreme flight path angle (FPA)), the automation will not engage when it is commanded, causing further breakdown in awareness.

- Pilots may have an incomplete understanding of the avionics. Wiener (1989) showed that even experienced pilots felt that they had gaps in their knowledge of how the automaton functioned. They frequently reported being startled into asking "What is it doing now?" and wondering "Why is it doing that?" and "What is it going to do next?"

- Pilots have to figure out how to get beyond the "gulfs." Hutchins et al. (1986) describe both a "gulf of execution" and a "gulf of evaluation" that are sometimes perceived by the pilot in relation to the avionics. The gulf of execution occurs when there is a mismatch between pilot's intentions and the interface provided for communicating those intentions to the automation. In these cases, it is not readily apparent to the pilot how to make the desired changes to the system. The gulf of evaluation is the inability to evaluate the current state of the avionics. This latter gulf occurs when programming errors are not directly evident to the flight crew. Here, the flight crew may believe they are going to one waypoint when in fact the avionics are programmed to go to another. 
Studies of pilot understanding about avionics have indicated that pilots are uncomfortable with autoflight systems and that these systems are probably the least understood aspect of flight in modem jets. Wiener (1989) provided evidence that identified the autoflight system as one that pilots did not understand well. In his study, he asked almost 300 pilots to rate their agreement with the following statement: "In the Boeing 757 automation, there are still things that happen that surprise me." Results indicated that about $55 \%$ of the pilots agreed with that statement. About $30 \%$ of the pilots agreed with a second statement, "There are still modes and features of the B-757 that I don't understand."

Sarter and Woods (1992) replicated Wiener's findings for the Airbus A-320. In their study, $67 \%$ of pilots agreed with the surprise statement that was mentioned above. They also showed that $40 \%$ of the pilots in their study agreed with the second statement about not understanding the airplane's modes and features completely. Pilots attributed their lowered understanding of vertical navigation to their inability to visualize the vertical path that the airplane was flying, difficulty in predicting vertical navigation behavior, and an incomplete understanding of the system.

Palmer et al. (1993) analyzed reports from the ASRS to provide an understanding of how pilots use the vertical navigation system. They report that the ASRS receives about 8000 altitude deviation reports over the course of one year, nearly one per hour. Some of the reported causes for these deviations include crew distraction, pilot complacency, misunderstanding of air traffic control (ATC) communications, misunderstanding of within-cockpit communications, pilot fatigue, inexperience of pilots, and lack of pilot understanding of the autoflight system.

\section{Pilot Training in Avionics}

Hutchins (1992) reports that training often lacks a robust conceptual and theoretical component. Line pilots are taught one method for solving a problem or applying the automation. They are not normally taught that there are alternative methods to do the same task or how these different methods interact. Additionally, current training seems to be based on rote memorization of procedures. Training consists of explaining when to perform a task and what should happen as a consequence. This type of training leaves much to be desired and has prompted several airline pilots to want to know more. Pilots would like to be able to ask and get answers for the following questions: "What problems does this solve?" and "When should I use this?" and "How does this help me to solve this problem that I am facing?"

Hutchins also suggests that training pilots in the conceptual framework of the airplane and its behavior should actually decrease training time. He points out that retention is much better when what is learned can be integrated into a conceptual framework. This is a basic tenant of training system design and should find its way into pilot training programs. An example is the current training for glass-cockpit aircraft. When students without glass experience are brought into classes, they are immediately exposed to procedures and task-response pairs. A first step may be to acquaint students with an overall conceptual understanding of the glass cockpit, how it uses computer technology to optimize the flight path, and an understanding of the different flight modes (Hutchins, 1992).

Crowther et al. (1994) suggest that pilots need an accurate and complete system knowledge to ensure that they do not misunderstand avionics modes. Crowther et al. presented a methodology for giving 
the vertical navigation information to the pilot in a computer-based training situation. Pilots were given a display of the vertical path of the airplane along with specific mode information and predictions of future modes. The results suggest that this type of information enhances pilot awareness of vertical guidance modes.

\section{PART 1-SURVEY}

The survey was developed as a first step in the research project and to get a deeper understanding of how pilots fly the airplane, how they use the existing displays, and what automation surprises they have seen with the MD-11. This section will describe the first of the two-part study on understanding vertical navigation.

\section{Survey Methods}

The questionnaire was developed by several people, each with a unique expertise about flying. Each person on the team provided a unique viewpoint and expertise that was used to create a complete and comprehensive survey. Team members included an MD-11 pilot and evaluator, human factors specialists, cognitive psychologists, and avionics system/software engineers.

Once the team developed the questions that they wanted to ask, we used data developed for constructing questionnaires to anchor the scaling of the questionnaire items. We chose to scale most of the questions in terms of the frequency that pilots observed an event or performed a task. The scale was constructed using adverb descriptors that had the following scale values:

- Always (8.99)

- Usually (7.17)

- Occasionally (4.13)

- $\operatorname{Seldom}(2.45)$

- $\quad$ Never (1.00)

These response values have been obtained in previous research and represent a balanced scale composed of clear terms. The scale values indicate the mean rankings of each of the adverbs on a scale of one to ten. Using these numbered anchors allowed us to be certain that a continuum was being used and that there was separation between adjectives (Babbitt and Nystrom, 1989). The final form of the questionnaire as given to pilots is provided in Appendix A.

Data were collected using mail surveys. The surveys were given to all line pilots currently flying the MD-11 airplane at Federal Express by mailing them out to pilots with their April bid packages. The bid packs contain the information on flights that pilots need to set up their schedules for the next 
month. To make it easier for pilots to fill out and return their surveys, we included an addressed, stamped envelope. The questionnaire was distributed with a cover sheet and it contained three pages of multiple choice items and one page of open-ended questions (Appendix A).

Pilots returned 203 surveys over the months of May through August (37\% overall return rate). The mail survey method was effective with this population and we received a complete data set from the pilots participating. Missing variables were minimal and we obtained numerous comments from pilots in the open-ended question section included with the survey. One pilot submitted an additional five pages of comments to annex the open-ended section. This shows the dedication and interest of the pilot population in assisting with research. Typical marketing research surveys have a return rate of about 10 to $15 \%$; our return rate was exceptional for this type of survey.

\section{Survey Participants}

The majority of pilots who filled out the survey had not flown a glass cockpit before coming to the MD-11. Only 46 participants (23\%) reported that they had flown in jets with glass cockpits. Almost half of the sample of pilots came from the B-727, an airplane without automation. Pilots were split on experience in the MD-11, with 91 respondents (45\%) reporting over 1000 hours in the jet. The remainder reported between 100 and 1000 hours in the current airplane.

We found a fairly even split between first officers (44\%) and captains (50\%) who participated in the study (the remaining $6 \%$ were either from Flight Standards or Flex Instructors, which in this company indicates that they were captains). About $65 \%$ of the respondents had over 7000 hours flying fixed wing airplanes and $50 \%$ had some military flying experience. Twenty-six percent of pilots were under 40 years of age and the remaining $74 \%$ were distributed over age ranges of $41-50(47 \%)$ and $50-59$ $(28 \%)$.

\section{Survey Results}

\section{Rating Scales}

Pilots filled out several rating scales looking at their evaluation of training, types of automation surprises they have seen, and other scales concerning the displays and information that is displayed. These ratings are summarized in this section. Open-ended comments, which were a part of the questionnaire, are summarized in the next section.

Use of Automation- Seven questions were asked about the pilot's use of PROF (an abbreviation for profile mode) in the airplane. PROF, the automated vertical guidance mode of the FMS, is frequently misunderstood by line pilots, and questions were asked to explore when pilots used the profile mode of operation during normal flights. Results showed that pilots used PROF extensively during the climb phase of flight, less during descent, and more infrequently when in the approach phase (table B-1 in Appendix B).

Modification of Automation- Additionally, we asked pilots to tell us how often they modified the flight plan to optimize the use of PROF in the airplane (table B-2, Appendix B). These questions were 
used to help us understand how many pilots enter additional data into the FMS to optimize the flight path. These questions showed that pilots had different styles of using the automation. While $94 \%$ reported that they will usually or always edit the flight plan page, $76 \%$ stated they would erase tumpoints or their present position to build an approach. About $56 \%$ of respondents stated that they routinely input wind and temperature data on the Descent Forecast Page to improve the flight path. Finally, pilots routinely use the "Direct To" function with a course intercept when they are vectored to a final approach $(51 \%)$.

Use of Current FMA and Interpretation of Display Information-Five questions asked pilots to tell us how frequently they used different displays (or areas of displays) in the cockpit to interpret what the airplane was doing. These displays present information to pilots and are designed to aid monitoring of the different functions on the airplane. Pilots reported using the following to monitor the information from the avionics either "always" or "usually" (see table B-3, Appendix B, for complete information):

- FMA (59\%)

- Navigation display (ND) (89\%)

- $\quad$ Speed tape $(98 \%)$

- Altitude tape (94\%)

- Flight plan page (75\%)

Automation Surprises- An automation surprise occurs when the automation commands a maneuver that the pilot is not expecting. We asked pilots to rate the frequency of the automation surprises that they had seen personally (table B-4, Appendix B). Most frequent surprises (reported as occasional, usual, or always) were decelerations too early [in descent and approach] (64\%), unexplained altitude errors $(58 \%)$, unpredictable speed targets $(47 \%)$, failure to make altitude restrictions $(43 \%)$, and unexplained error messages (39\%).

Training Topics- We asked pilots to rate specific training topics dealing with vertical navigation. For each topic, pilots told us whether they felt it was thoroughly taught in the existing courses provided by the company. If they indicated that more training was needed, we asked them to tell us if the training should be part of either the initial or recurrent pilot training courses. Responses indicated that pilots had mixed feelings about what needed to be trained beyond what was taught in the company programs. Less than one quarter of the pilots felt that the following training topics were adequately covered (table B-5, Appendix B): FMS Speed Logic, understanding PROF vertical navigation (VNAV), interpretation of the FMA, and optimal VNAV.

\section{Open-Ended Comments}

Additionally, pilots were asked to provide comments on four topics: use of automated vertical navigation, interpretation of the FMA, automation surprises, and training. For each category, between 45 and 80 pilots filled in comments on this last page of the questionnaire. The comments have been 
summarized in Appendix B under topic categories with the number of comments in this category following the short name of the topic.

Use of PROF- Pilots felt that PROF was difficult to use when the plane was in descent less than 10,000 feet. They also felt that the plane slows down too early in this mode. An additional group of pilots liked using PROF and thought that it was a great system. Pilots reported that they felt that they needed experience to use PROF and feel comfortable with it. One pilot stated a need for at least 60 landings in the system to achieve proficiency. Pilots also felt that there were many ways to improperly set up the system (pilot-entered data) so that problems were created later in the flight.

FMA and Symbology- Pilots reported that they liked the current FMA and had no problems with it or symbology in general. Pilots wanted an FMA trainer and more training in interpretation of the displays.

Automation Surprises- Pilots pointed out that there were fewer surprises due to a maturing of FMS products. Surprises also were reported to come from misunderstanding the system. Many errors are pilot induced but these decrease with experience. When pilots don't know how the system works, it is easy to be surprised. Several comments indicated that the plane slows too early and the FMS Speed mode causes surprises.

Training- Pilots reported that they needed more training on the FMS, an FMS trainer, and learning aids to help learn the system. Pilots suggested that trainers stick to a basic approach to training, teach the "must know" parts first, "should know" parts second, and then go into "nice to know" aspects.

\section{Implications}

The questionnaire results confirmed that many of the constructs discussed in the literature are happening out on the line with pilots every day. The questions on automation surprises showed that these are occurring in glass-cockpit aircraft in a variety of situations, especially during the descent and approach phases of flight.

The demographic information collected showed that pilots were experienced in flying fixed-wing airplanes but not necessarily experienced in flying with glass cockpits. Since the methods of flying glass and non-glass airplanes are different, this identifies a need to start training with the basics. For example, trainers should describe the underlying function of the computer system before focusing on how the aircraft will react to different inputs while flying. Currently pilots are using the full automation in climb and cruise consistently, but only occasionally are they using this power in the descent flight phases. To take a look at this situation, the entire flight system needs to be addressed, including air traffic controller awareness.

When it comes to automation surprises, pilots do report these and have experience trying to deal with an aircraft that is not behaving exactly as expected. Pilots believe that these surprises are due to the level of experience of the pilot, the design of the system, the complexities of dealing with the descent and approach phases of flight, and the pilot's level of system trust. Each of these aspects has specific design and implementation applications. 


\section{PART 2-EXPERIMENT}

Based on the results of the survey, the team decided to evaluate both an experimental FMA and a training package to accompany the new display. The annunciator and training material were derived from a formal methodology used for the requirements specification, known as the Operational Procedures Model (Sherry et al., 1995). The content for the model came from a representation of the actual vertical guidance logic and developed into a model of the interaction between the components, referred to as the Cockpit System Model.

\section{The Cockpit System}

The function and structure of a modern avionics system are determined by its mission (Billings, 1997; McRuer et al., 1973; Spitzer, 1987). The mission of a commercial airplane is to transport passengers and cargo from an origin to a destination. This mission is accomplished in the presence of constraints including weather, air traffic, airspace regulations, airline policies, standard operating procedures, the performance limits of the aircraft, and the capabilities of the airline's infrastructure.

Performance of the mission can be decomposed into five tasks (fig. 1): flight planning, navigation, guidance, control, and stability augmentation. These task elements are shared between the pilot and the automation, and are related to the task decomposition taught to student pilots: aviate, navigate, and communicate. Other authors describe related decompositions that partition the tasks differently or include other pilot responsibilities (Billings, 1997; McRuer et al., 1973).

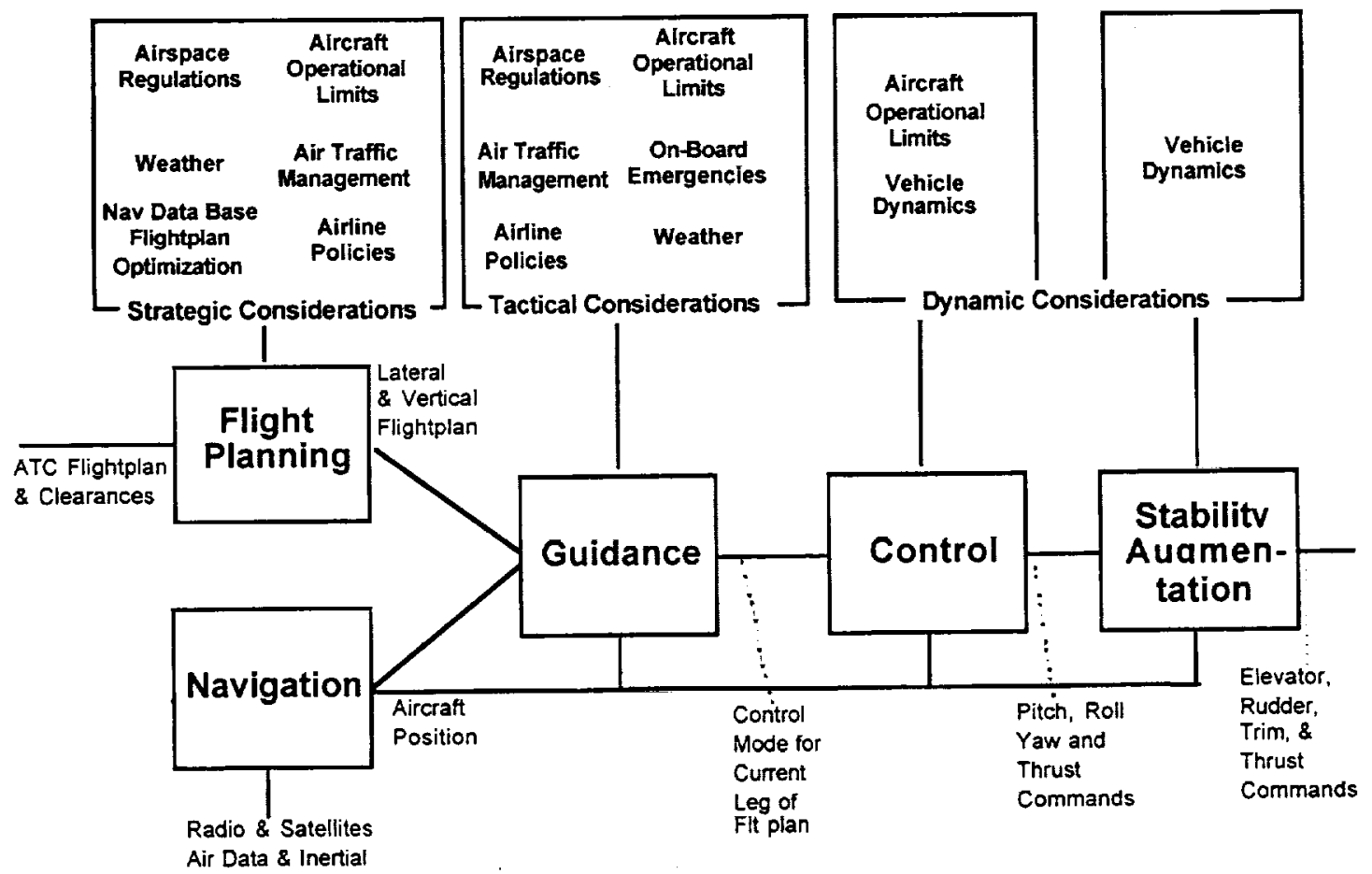

Figure 1. Functional breakdown of the cockpit system. 
The flight planning task element requires computation of the route segments for a given flight to define a trajectory from the origin airport to the destination. The route is defined by both a lateral and a vertical flight plan. The lateral flight plan is described as a series of waypoints linked together by lateral legs. The vertical flight plan specifies altitude, speed, time constraints, FPAs, glideslopes, and an Earth-referenced approach path. The generation of an appropriate flight plan in both a vertical and lateral sense requires knowledge of airspace regulations, airline policies, aircraft performance limits, passenger-comfort considerations, weather conditions, airline cost index, and required time of flight.

The navigation task element determines the position of the aircraft at a given point along the flight path by integrating information from air-data sensors, inertial sensors, and radio data. Many aircraft also include satellite position sensors from a Global Positioning System.

The guidance task element compares the actual position of the aircraft with the current leg of the lateral and vertical flight plan to generate a set of targets and control modes. Targets include aircraft heading, altitude, speed, FPA, vertical speed, and thrust. Control modes define the parameters that are controlled to achieve these targets. Lateral axis control modes, such as heading, adjust the aircraft roll and yaw to maintain the aircraft along a target heading to the next waypoint. Vertical axis control modes define the position of the elevators and throttles to control the altitude of the aircraft. The vertical control modes can include the following types of speed and altitude control:

- Speed controlled via the elevators with maximum thrust

- Speed controlled via the elevators with idle thrust

- Vertical speed controlled via the elevators with speed controlled via throttles

- Altitude controlled via the elevators and speed controlled via throttles

The targets and control modes are selected by the comparison of the current position of the aircraft relative to the upcoming flight plan. Adequate allocation of targets and control modes must weigh many of the factors that were mentioned above under the flight planning task.

Sherry et al. (1996) identified 289 rules for selecting targets and control modes in the PROF Guidance software. Interestingly, the current avionics suite does not annunciate the guidance function or the origin of the targets and control modes. These must be inferred by the pilot after checking several sources of information available in the cockpit. A central tenet of this research project is that the pilot who understands the system and has a good understanding of the state of the guidance task will be a much more competent pilot who will avoid automation surprises.

The control task adjusts the pitch, roll, yaw, and thrust of the aircraft to maintain guidance targets. This function includes standard automation equipment, such as autothrottles, autopilot, and navigation systems. When the control function is delegated to the automation, the pilot becomes an observer or monitor of information in the cockpit and does not provide manual inputs to the controls. The aircraft also uses a stability augmentation function to convert control commands into specific elevator, rudder, trim, and engine settings. Both functions perform aircraft control by using feedback from the aircraft, knowledge of vehicle dynamics, and the position of the plane relative to upcoming targets. 
The characteristics of the four main tasks (not considering stability augmentation) have important implications for both annunciation and training. Mangold and Eldredge (1995) view the problem of annunciation as containing information about:

- The instantaneous state of the aircraft

- The expected behavior of the aircraft for the next several minutes

- The strategic view of the overall mission

Annunciation of the first view is based on feedback obtained from the current state of the control task. The second and third views require feedback from higher level sources, such as the guidance and flight planning tasks, respectively. It is critical for pilots to understand all of the cockpit system components.

Current glass-cockpit aircraft use annunciation schemes that were designed based on the displays found in an earlier generation of avionics systems (i.e., DC-10 and B-727). This earlier generation of avionics displayed the results of navigation, control, and stability augmentation tasks only. Because guidance was not automated, it was not annunciated on a cockpit display. In the latest generation of airplanes, navigation, control, and flight planning tasks are partially annunciated and trained. The guidance function, however, is not directly annunciated and is hidden from the pilots with the current designs. Also, guidance is not treated as a separate topic in training although a limited amount of information about the guidance function can be found in the latest editions of the FMS reference manuals for the MD-11, A-320, A340, B-777, and B-747-400. Researchers do not make sharp distinctions between guidance and control functions; they lump them together under the topics of avionics modes, mode awareness, and annunciation (e.g., Billings, 1997; Hutchins, 1996).

The state of the guidance task can be inferred by an individual with detailed knowledge of its underlying logic and by integrating information from the primary flight display (PFD), FMA, ND, and various MCDU pages. However, pilots do not receive the necessary training to make these detailed inferences about the avionics, and integrating the information is a difficult process without this training.

Annunciating guidance provides pilots with a representation of the current flight segments, including the details on the currently selected control mode, expected path, target values, limits, and feedback on whether the aircraft will actually achieve the target values. Eldredge et al. (1992) point out that many circumstances described in the ASRS reports were caused by the fact that pilots had no way to determine whether an aircraft trajectory would meet a crossing restriction or some other constraint included in the current clearance. Pilots have also reported being surprised by the automation's selection of a control mode and corresponding target values (Vakil et al., 1995b). Extended training on vertical guidance and annunciation could reduce the occurrence of both circumstances.

In summary, current cockpit designs hide the guidance task and pilots receive little or no training on the behavior of this task. The behavior of the guidance task and the selection of control modes and their targets determine the current and future behavior of the aircraft. It is proposed that poor knowledge of the guidance logic causes pilots to have difficulty understanding the avionics' selections of 
modes and targets. Pilots may also have problems anticipating the behavior of the aircraft under these conditions, which leads to automation surprises.

\section{Design of the G-FMA}

The design of the existing MD-11 FMA and the proposed experimental annunciation display, referred to as the G-FMA, are shown in figure 2. This display was based on the Intentional FMA Design Project that was led by Lance Sherry (Sherry and Polson, 1996). Appendix G shows more information on this display and how it would function as an annunciator. The two main speed control modes are pitch and thrust. In a pitch speed control mode, the airplane speed is controlled by changing the pitch of the airplane, with a constant thrust setting. The opposite of this is the thrust speed control mode; this varies the thrust of the aircraft to control speed, while the pitch of the aircraft remains fairly constant (as in cruise flight).

The altitude control mode can be viewed as the converse of the speed control mode. Figure 2 shows speed as controlled by pitch, which therefore leaves altitude to be at a constant climb thrust setting while climbing to the altitude target. If speed was controlled by thrust, the altitude target would be reached by varying the pitch. An example of this is a vertical speed climb, which specifies the rate at which the airplane climbs and holds a target airspeed by varying thrust.
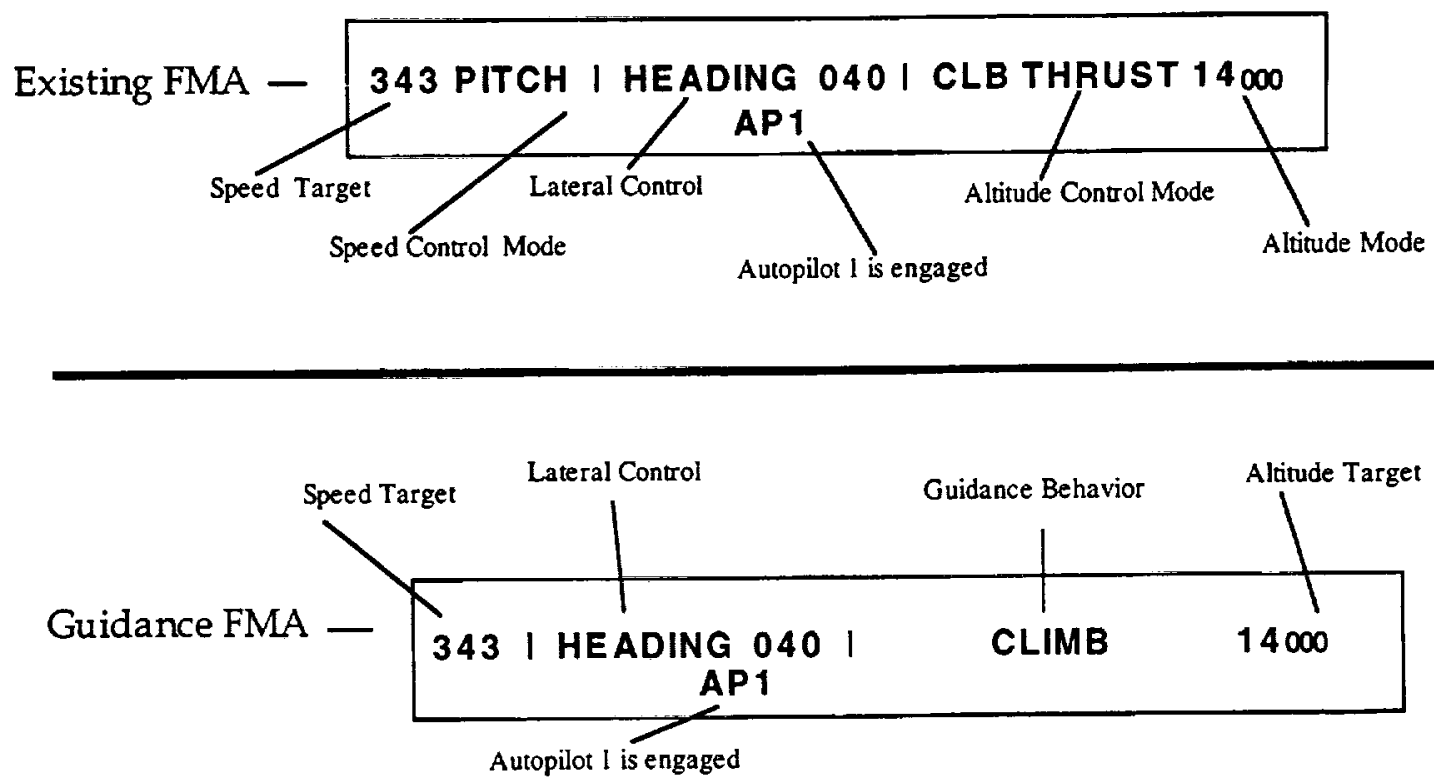

Figure 2. Diagrams showing the existing MD-II FMA and the guidance model. Note: Presentation on the PFD is white or magenta text on black background. 
The altitude control mode window can display several values or modes:

- Takeoff (T/O) thrust

- T/O clamp

- Climb (CLB) thrust

- Hold

- Maximum continuous thrust (MCT)

- Vertical speed (V/S)

- FPA

- PROF (or VNAV mode)

- Idle

- Idle clamp

These annunciations are presented in combinations. For example, possible annunciations for descent are either PITCH and IDLE or THRUST and V/S. The combinations PITCH and PROF, or THRUST and IDLE will never be seen. These combinations of annunciations may not be exclusive either. For example, PITCH and IDLE are used as the annunciation for more than three different aircraft behaviors.

The G-FMA presents the mode information differently. Instead of having two modes that give information about how the aircraft is being controlled, which requires a translation to interpret the behavior of the aircraft, the G-FMA uses one annunciation that describes the overall behavior of the aircraft. The behavior names simplify the vertical guidance logic by eliminating the transformation from the control mode information to the behavior. This overall behavior name consists of one of the following (under normal operations):

- Climb

- Climb intermediate level

- Cruise

- Descent

- Early descent 
- Late descent

- Descent intermediate level

- Descent overspeed

Most of these labels have an intuitive meaning to pilots, but a few require a deeper understanding of the vertical guidance system. In these cases, if the pilot does not understand the meaning of the annunciation, it is difficult to ignore.

Feary et al. (1997) show an example of this by comparing the LATE DESCENT and DESCENT PATH OVERSPEED behaviors. Aircraft with FMS calculate a descent path that is the most efficient way to descend the aircraft. This is referred to as the optimum descent path. In the MD-11, the LATE DESCENT behavior was developed to cope with the situation that arises when the aircraft is forced to fly beyond the optimum descent path. The view of the pilots on the design team for this situation was that the airplane will continue to have excessive energy until it has returned to the optimum descent path. The goal of the automation is to return to the optimum descent path as quickly as possible once the airplane is allowed to descend. This objective is achieved by descending with speed on pitch and the throttles at idle, to a faster speed target (approximately 10 knots below the maximum speed limit).

This contrasts with another behavior, PATH DESCENT OVERSPEED, which was designed to handle situations in which the initial calculation of the optimum descent path resulted in a path that was too steep. The optimum descent path naturally shallows out in the later stages of the descent, so the objective of this behavior is to hold the speed of the airplane constant, and wait for the optimum descent path to "catch up" with the airplane. This behavior is also achieved with speed on pitch and idle thrust, but it uses the optimum descent path speed target, which is slower than the LATE DESCENT speed target.

Seen in the illustration following, the Control-FMA annunciations are essentially the same, with the exception of the different speed target annunciation. In comparison, the G-FMA shows a difference in the objective of the behavior of the aircraft.

The differences between these behaviors have operational meaning for pilots. To illustrate, the higher speed target in LATE DESCENT may take some pilots by surprise if they are not aware of the objective of trying to return to the optimum descent path as quickly as possible. Additionally, because LATE DESCENT reflects the aircraft position beyond the path, the pilot should be aware that the possibility of not making a waypoint altitude restriction has increased. Another difference is that PATH DESCENT OVERSPEED is an automatic speed protection behavior which is not pilot initiated, unlike the LATE DESCENT behavior. 
Existing MD-11 FMA Annunciation for PATH DESCENT OVERSPEED:

340 PITCH I NAV1 I IDLE 14000

FMA Annunciation for LATE DESCENT:

355 PITCH I NAV1 I IDLE 14000

G-FMA Annunciation for PATH DESCENT OVERSPEED:

340 I NAV1 I DESCENT OVERSPEED 14000

G-FMA Annunciation for LATE DESCENT:

355 I NAV1 I LATE DESCENT 14000

The lack of difference in annunciation and appropriate training for the annunciation results in a system which may appear to be unpredictable to the pilot. If a system is unpredictable, evaluation and acquisition of knowledge about the system becomes very difficult. Evaluation of the system becomes difficult because the pilot is unable to determine the "intent" of the automation or diagnose a mismatch between the pilot's goals and those of the automation. Acquisition of rules about the behavior of the automation is made difficult because it is unclear which information should be retained.

Knowing the behavior name should also assist pilots with predicting the next vertical modes because of the generally accepted sequence of events during a normal flight. For example, in a nominal flight, CLIMB will precede long range CRUTSE, then proceed to PATH DESCENT. The annunciations should reflect this normal progression through the phases of flight and limit the number of deviations from the nominal flight phase progression, which should aid prediction.

\section{Simulator Study Methods}

The second half of the study took the information obtained from the questionnaire analysis and developed a training program and annunciation that took some of the issues mentioned by pilots and used them in the design process. A sample of the format used in this training program can be found in Appendix C. Feary (1997) provides a more complete description of the training program, including the basis for the tutor and how it was developed, along with the prototype display used for the evaluation.

The study used three conditions so that adequate baselines could be established for comparison. All three conditions consisted of current MD-11 pilots with at least one year of experience on the airplane. 
The baseline condition consisted of pilots who flew the simulation without training and with the existing FMA on the MD-11. The second condition, training, had participants go through a training program on vertical guidance techniques. This training explained how to read current FMA displays and how to infer the behavior of the airplane from the displayed information. In the third condition, display, the participants went through the training program and then flew the scenario with the new G-FMA display. The baseline and training groups used the existing MD-11 displays for their flight scenarios.

\section{Experimental Participants}

Twenty-seven MD-11 pilots participated in the study; 25 were from Federal Express and 2 were from Swiss Air. Participants were randomly assigned to conditions prior to their coming to Long Beach, California, where the simulator was located. There was a significant effect of experience that was found among the three conditions. This effect is described in the Results section.

We had an fairly even split between captains and first officers in the study. There were 11 captains and 16 first officers that participated. We also asked pilots to tell us what seat they had flown in prior to coming to the MD-11. Twelve of the pilots came from the captain's seat, 8 came in as a first officer, and 7 were second officers/flight engineers on the other aircraft. Previous planes for pilots included the B-727 (in 15 cases), B-747 (4 cases), DC-10 (5 cases), MD-11 ( 1 case), A300 (1 case), and Fokker 100 ( 1 case).

\section{Training/Vertical Navigation Tutor}

Participants were given a tutor that was developed to provide an overview of the vertical navigation concepts, an introduction to the operational procedures for normal operations, and an increased understanding of the MD-11 system (Feary, 1997). A sample of the tutor for late descent is included in Appendix B. The following vertical guidance topics were covered in the tutor:

\section{- FMA}

- Glareshield control panel (GCP) operations

- Altitude change methods

- Optimum altitude selection

- Flight phases

- Vertical guidance operations

- Vertical profile performance

- Descent performance changes 
Training was given to participants in the training and display conditions only. In each of the two conditions, the training was presented on a laptop computer the night before the simulator flight. Training took approximately 1.5 to 2 hours to finish, with one exception. We gave the training the night before the flights so that it would still be fresh in the pilots' minds while allowing them some time to process the information before they had to use it.

The training in the display condition showed the new G-FMA in all of the FMA pictures. For the training condition, regular MD-11 FMAs were used. All of the training materials, graphs, and other information were the same for the two conditions.

\section{Experimental Flight}

A line-oriented flight scenario was developed to test the understanding of the participants. The flight was from Portland, Oregon, to Seattle, Washington, and took advantage of the Seattle FMS transition into runway $16 \mathrm{R}$. For each flight, the pilot participant was designated as the "Pilot Flying," while the experimenter was the "Pilot Not Flying" and the "ATC information source." The pilots were instructed at the beginning of the flight that they were to keep the system in full automatic mode (PROF) for as long as possible en route. The experimenter set up the airplane configuration and readied the FMS for departure.

At eight points during the flight, the simulator was stopped so that we could ask pilots questions about their understanding of the avionics. In response, the pilots told us

- What the airplane was doing now

- What it would do next given a change to the system

- What the FMA would look like when the next condition was to take place

Appendix D presents the entire scenario that was used and shows when the stops were made in the procedure.

This method of stopping the simulator, asking the pilot some questions, and restarting it is a modification of a methodology referred to as the situation awareness global assessment technique (SAGAT) (Endsley, 1995). We modified this technique for use with commercial aircraft operations. The first modification involved placing the stop events at fixed points, rather than at a random assignment. Additionally, we did not blank the PFDs, because in commercial aircraft operations, pilots have that information available, with less time pressure in most cases.

\section{MD-11 Simulator}

The simulator used is located at the Boeing Company-Douglas Products Division Facility in Long Beach. Although this device had full visual capability, we chose not to use these visual displays for our test to allow the pilot to focus on the MD-11 displays. The device did not have any motion 
capability. Pilots remarked that the FTD was similar to a real MD-11 and there were no shortcomings noted (see the Results section for a full presentation of pilot ratings of the simulation).

\section{Software Changes}

In order to get the G-FMA to be displayed on the simulator PFD, changes were made to the display electronics unit (DEU). This device manages the information that is displayed on the PFD; changes were made to the software to display the G-FMA (see fig. 2). To make this happen we needed airplane performance data from the flight test bus, available from the FMC. Since the FMC normally does not communicate with the DEU, a separate wire had to be installed to patch the FMC signals into a spare receiver on the DEU.

The FMC was configured with a current version of the Federal Express navigation database. This was required for the flight simulation because we used a customized FedEx FMS arrival at Seattle.

\section{Data Collection}

The data collected in the study included paper quiz information, whiz-wheel display collection, videotape record, and behavioral observations. Each will be reviewed in more detail below.

- Flight Quizzes. At each stop in the scenario, pilots were asked to fill out a paper and pencil form asking them to identify the origins of the current speed and altitude targets. Additionally, we asked them to identify the behavior of the aircraft. At each stop, we asked pilots to do this for the current situation and for the next event in the scenario. Figure 3 shows a sheet that was used to assess understanding of the current situation, which was at an intermediate level during climb and when the was plane level at 19,000 feet. Figure 4 shows the second half of the question where the pilots were asked what the airplane would be doing when climbing to 31,000 feet. By having the pilots answer both of these types of questions for each stop, we were able to gather information about what the pilots knew of their present condition and how well they understood what was next in the scenario. The same quizzes were used for all three groups during the course of collecting data during the experiment.

- FMA Template. The FMA template is a device built for this study consisting of a series of push/pull slide rules (figs. 5 and 6). At each stop, pilots were required to construct the FMA for the next flight event in the simulation. To do this, pilots moved the scales up or down until the correct word or value appeared in the window. Speed values of $240-360$ knots (in 5 knot values) were available on one side of the speed slide and Mach numbers $0.765-0.855$ on the other. Altitudes values of 1000-15,000 feet (in 1000 foot values) were printed on one side of the altitude slide and 16,000-33,000 feet on the other. Two altitude slides were available: white altitudes indicated that the pilot set the altitude with the GCP, and magenta meant that the altitude was from the FMS and was either in the flight plan or was a constraint from the FMS. 
21. Salect the torget and doscription for the current simention.

\begin{tabular}{|c|}
\hline Candidate Speod Target \\
\hline Econ Cund CAS \\
\hline Edxchocas \\
\hline 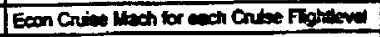 \\
\hline 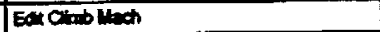 \\
\hline Ean Cinb Kach \\
\hline Max Augle Canb CAS \\
\hline
\end{tabular}

\begin{tabular}{|c|}
\hline Candlete Althude Tergat \\
\hline Cons fiphenal \\
\hline 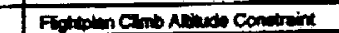 \\
\hline 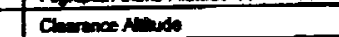 \\
\hline 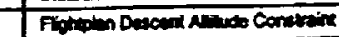 \\
\hline
\end{tabular}
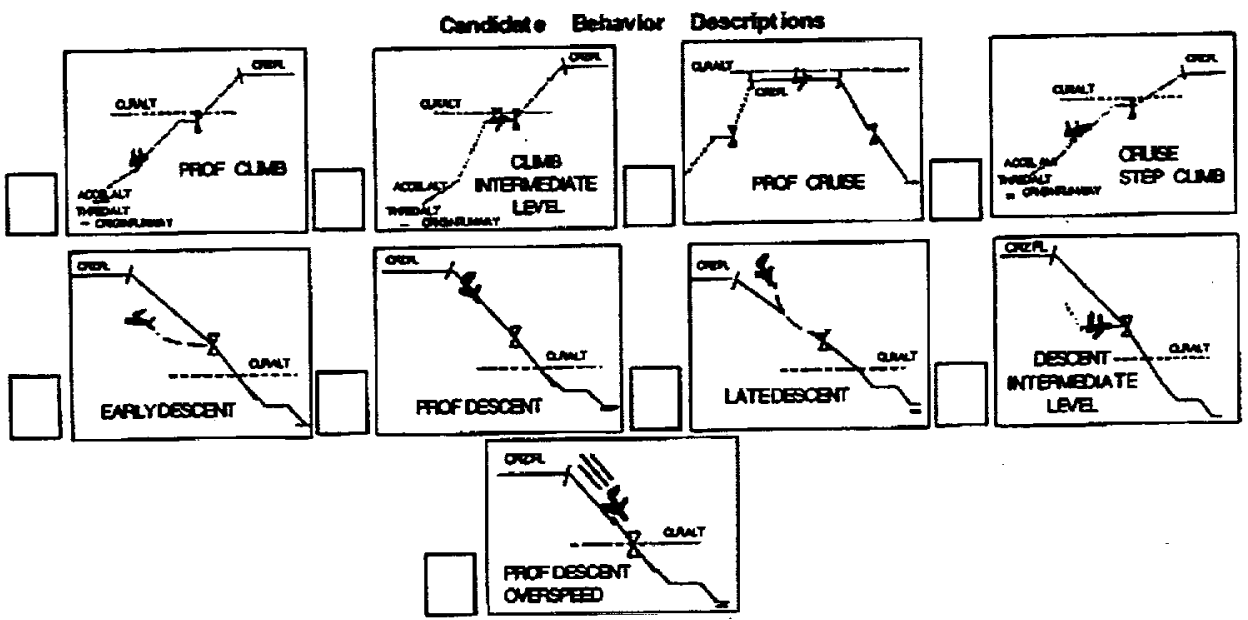

Figure 3. Flight quiz for the current situation.

28. Select the description and tergots you would expect to sas if the aircran was cleared to, and clinbing to Futo.

\begin{tabular}{|c|}
\hline Cendidate Spend Tanget \\
\hline Econ Clnb CAS \\
\hline EAt Ching CAS \\
\hline Eocon Critap Mach for eech Crise Finglower \\
\hline Eot Cinb Wach \\
\hline Max Ande Cinte CAS \\
\hline
\end{tabular}
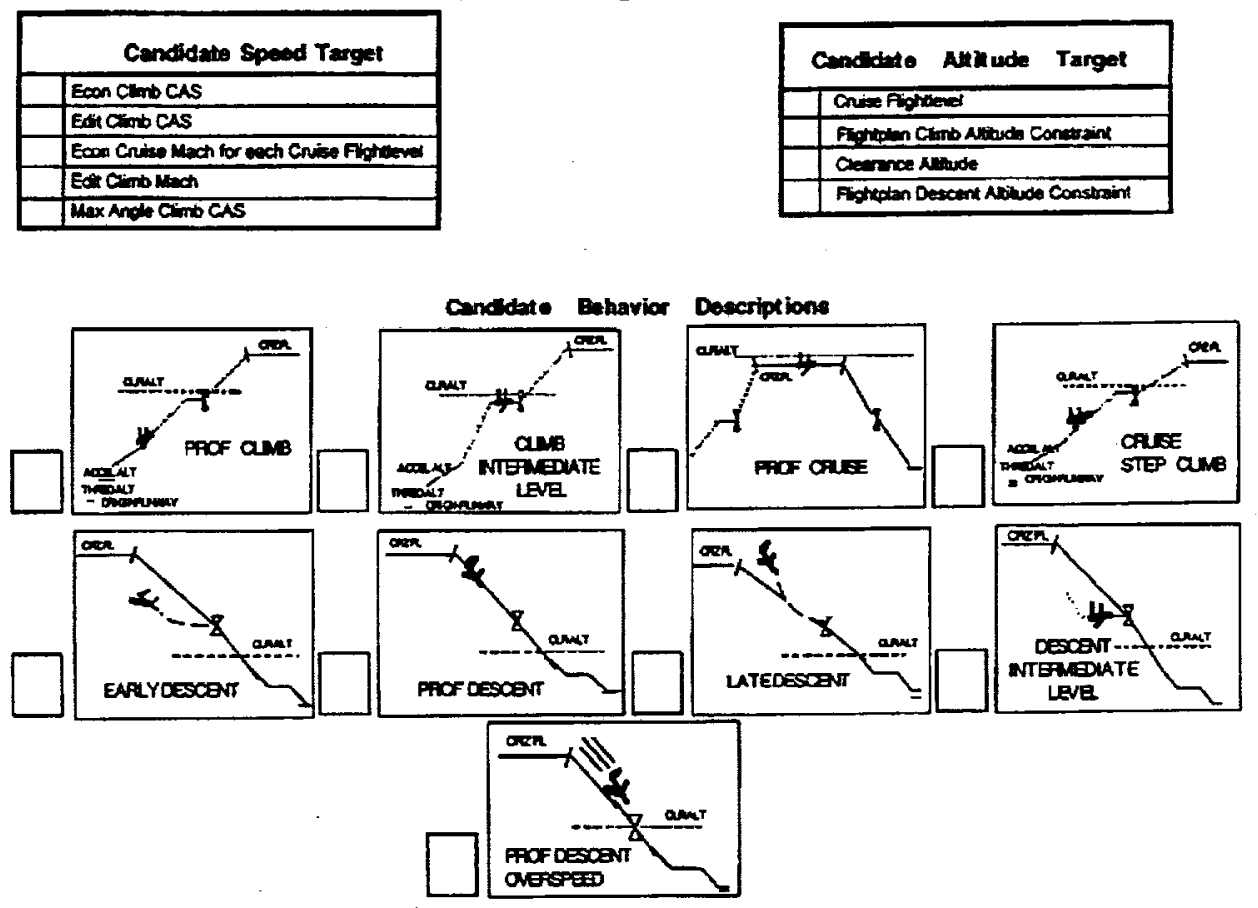

Figure 4. Flight quiz for the next situation. 


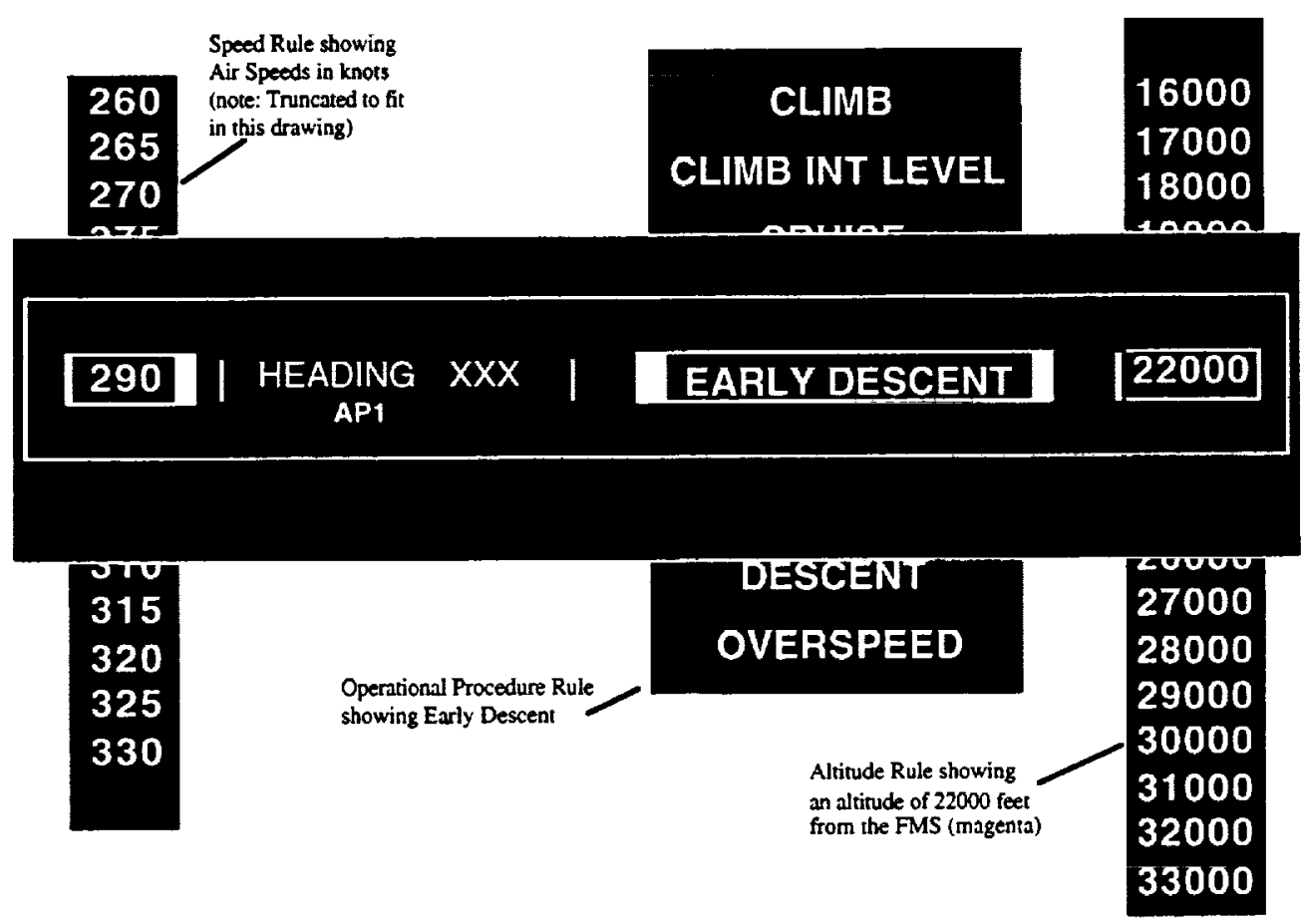

Figure 5. FMA template for the G-FMA condition.

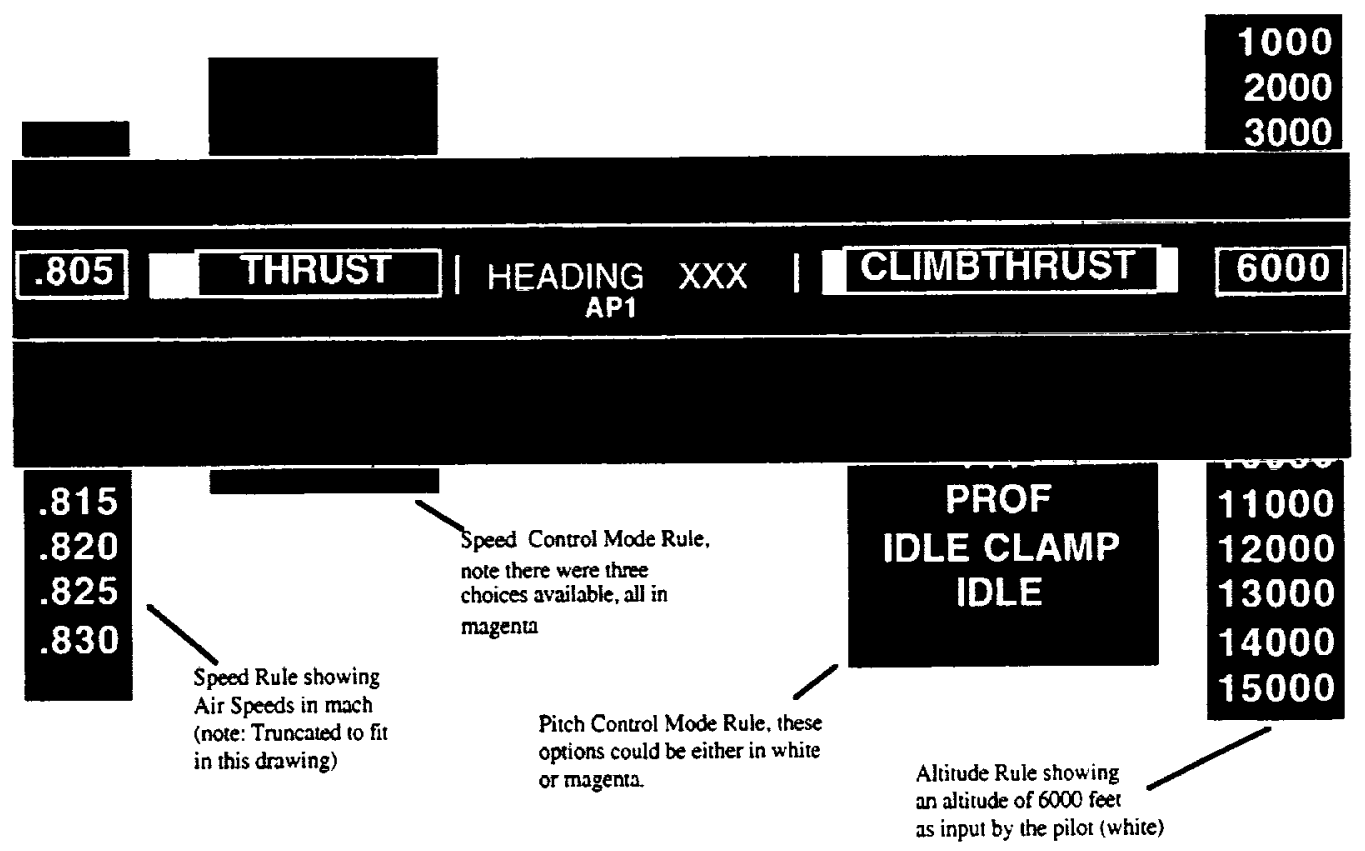

Figure 6. FMA template for the training and baseline conditions. 
In addition to speed and altitude, we also asked pilots to predict the next operational procedure (display condition) or tell us what the speed and pitch control modes were (training and control conditions). Two different FMA templates were created for the study and the appropriate one was used in each of the experimental runs.

- Videotape. Each experimental run was videotaped to preserve an "over-the-shoulder" view of the pilots. The videotaping was not a direct measure used in the study, but was done to preserve the flights and to allow post hoc data collection on an event or behavior that was not originally recorded in the study.

- Behavioral Observations. At one point during the scenario, we observed the pilots to see whether they exceeded a speed restriction that was placed on them at takeoff and whether they maintained the 250 knot speed restriction through 10,000 feet. The initial clearance was to maintain 250 knots until further advised. Normally, the plane will accelerate to 355 knots after passing 10,000 feet. Other behavioral observations are noted in the Results section.

\section{Experimental Results}

\section{Pilot Differences}

A difference was noted in the amount of time that the three experimental groups had logged on the MD-11. The control group reported a mean of 1672 hours; the training group, 1022 hours; and the display group, 604 hours. This difference was significant ( $\mathrm{df}=2,24 ; \mathrm{F}=3.96 ; \mathrm{p}=0.032$ ). We also asked participants what their previous airplane was and the number of hours that they spent in it. While it appeared as if the display condition was significantly less experienced on this scale (mean of 1311 hours), the differences between this group, the training group (mean of 1977 hours), and the baseline group (mean of 1905 hours) were not significant.

\section{Performance Differences}

Prediction of Next FMA using FMA Template- The most important finding was that the G-FMA condition could predict the future state of the avionics significantly better using the FMA template than could the baseline or training conditions. Specifically, pilots in the G-FMA condition could more accurately describe the future FMA annunciations for the composite index, which added the scores across the individual indices (scores for the behavior mode in the G-FMA condition were added twice to create equivalent scores). Pilots had a better understanding of the avionics and used the more descriptive annunciation to help them predict what the FMA was going to look like in the future. The difference between the training group and the baseline group was not significant, but there was a trend for the training group to have better scores than the baseline group. Overall prediction scores were $91 \%$ for the G-FMA condition, $86 \%$ for the training condition, and $79 \%$ for the baseline condition. These are shown in figure 7 and in more detail in Appendix F. 


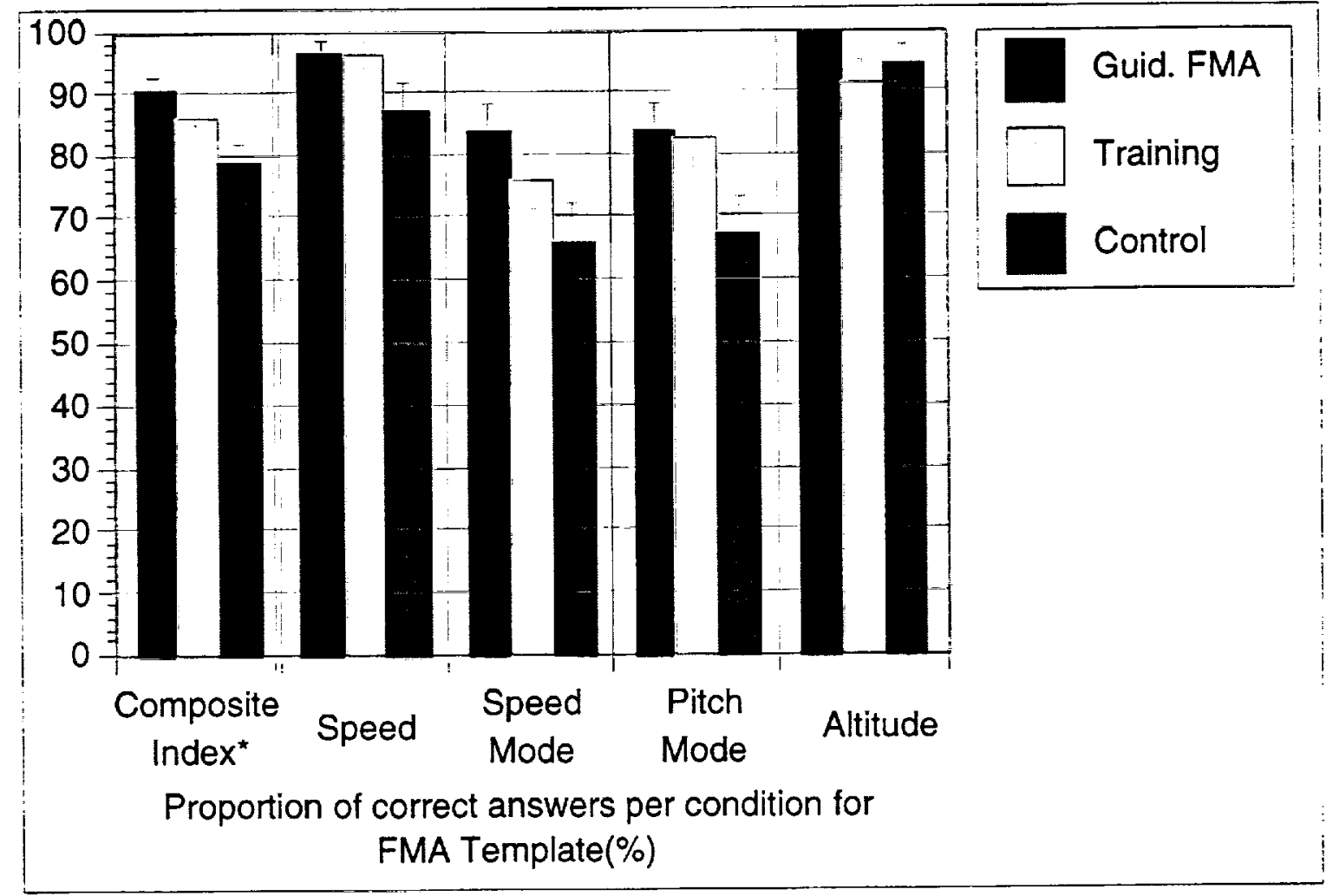

Figure 7. Results on FMA template.

Flight Quiz- The flight quiz data showed that there were significant differences between the groups for the composite index (added across the individual indices) and for the behavior and altitude indices. There was a significant difference between the baseline and G-FMA groups for the composite index, but neither the behavior index nor the altitude index had pairwise comparisons that were significant at the 0.05 level. These data support the notion that the understanding of the vertical guidance procedures was enhanced with the G-FMA and with training. Both of these groups had higher scores, indicating that they had more correct answers in these categories.

Current Situation Flight Quiz- The analysis of differences between the current and future stops proved interesting. As shown in figures 5 and 6 , we asked pilots to describe the current and next situations in terms of altitude target, speed target, and airplane behavior. The summaries for the current stops showed that the composite stop data (addition of altitude, speed, and behavior scores) and the behavior data were significantly different when comparing the G-FMA group with the baseline group. Scores for the three groups (G-FMA, training, and baseline) on the composite index were $80 \%, 70 \%$, and $65 \%$, respectively. Looking at the number correct on just the behavior question showed the following differences: a score of $83 \%$ for the G-FMA group, $70 \%$ for the training group, and $60 \%$ for the baseline group. These are shown in figure 8 and in more detail in Appendix F. 


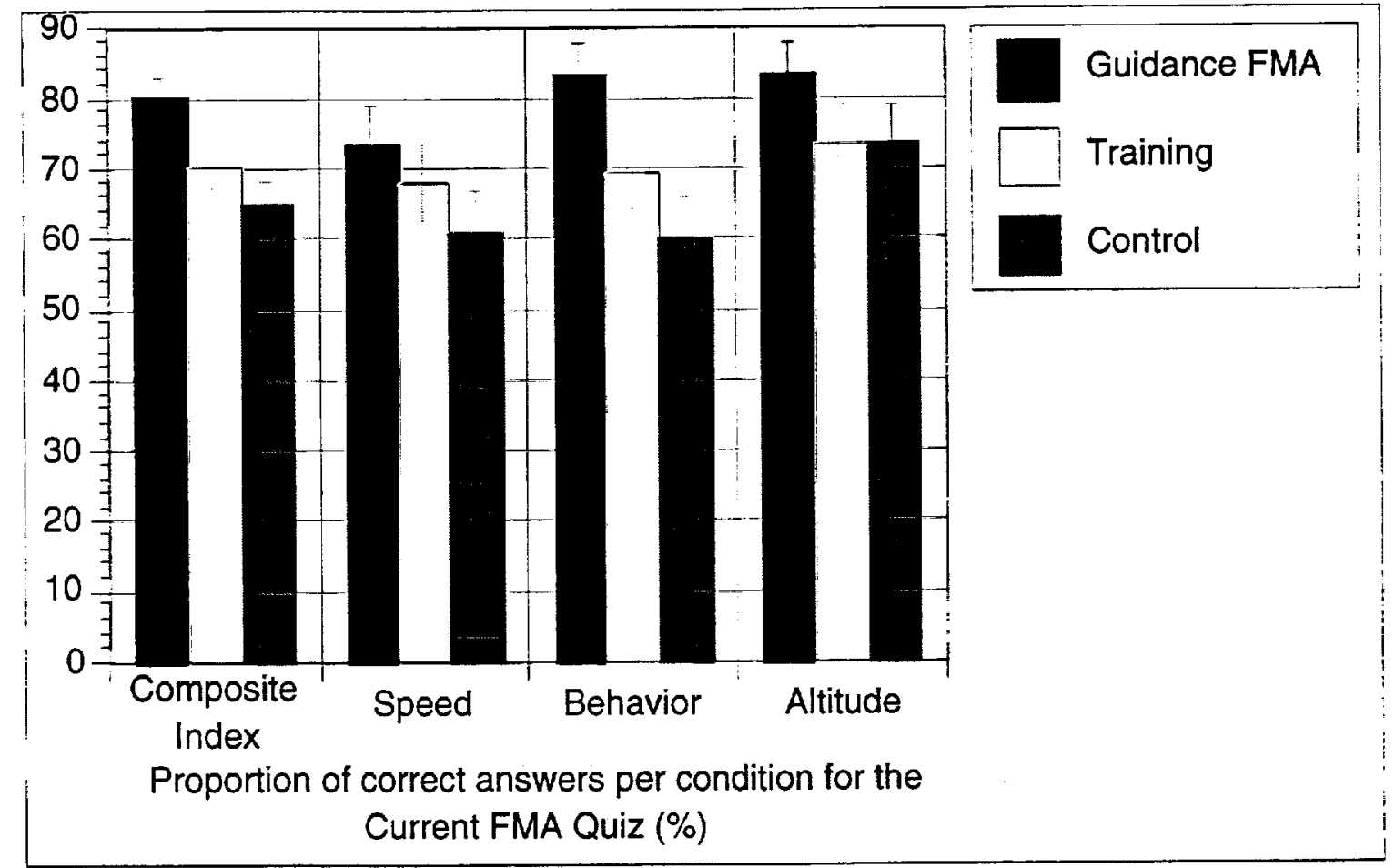

Figure 8. Results on flight quiz for current situation.

Next Situation Flight Quiz-For the next situation flight quiz, we found that pilots in the G-FMA condition performed better than pilots in the baseline group. On the composite index for the next situation flight quiz, pilots in the G-FMA condition had a score of $83 \%$, pilots in the training condition scored $77 \%$, and pilots in the baseline group scored $79 \%$. We also found a significant difference between the groups on the altitude question for this quiz. Pilots in the G-FMA (96\%) performed better than training condition pilots $(79 \%)$ and better than the baseline pilots (64\%). Looking at the pairwise comparisons, only the difference between the G-FMA condition and the baseline condition was significant. This indicated that groups that had the display and training were more accurate at predicting what the avionics would do next than was the baseline group. These data are shown in figure 9. Appendix F provides more detailed data on the flight quiz.

\section{Training Ratings}

A questionnaire was given to pilots to rate the characteristics of the tutor. The questions that were selected were similar to a set of questions developed by Feary et al. (1997) to rate the same tutor in another context. Only pilots in the display and training conditions rated the tutor, as these were the only groups that worked with this training program. There were no significant differences found between these two groups on any of the questions. Combined ratings of nine pilots from the display condition and eight pilots from the training condition did not yield any remarkable results. In general, pilots liked the training and felt that the session was worthwhile. Overall, 12 of the pilots thought the training was good or excellent. They liked the feedback and thought it was presented in a timely manner. Pilots also recommended that the training be used in both initial and recurrent training. Complete training results are presented in Appendix F. 


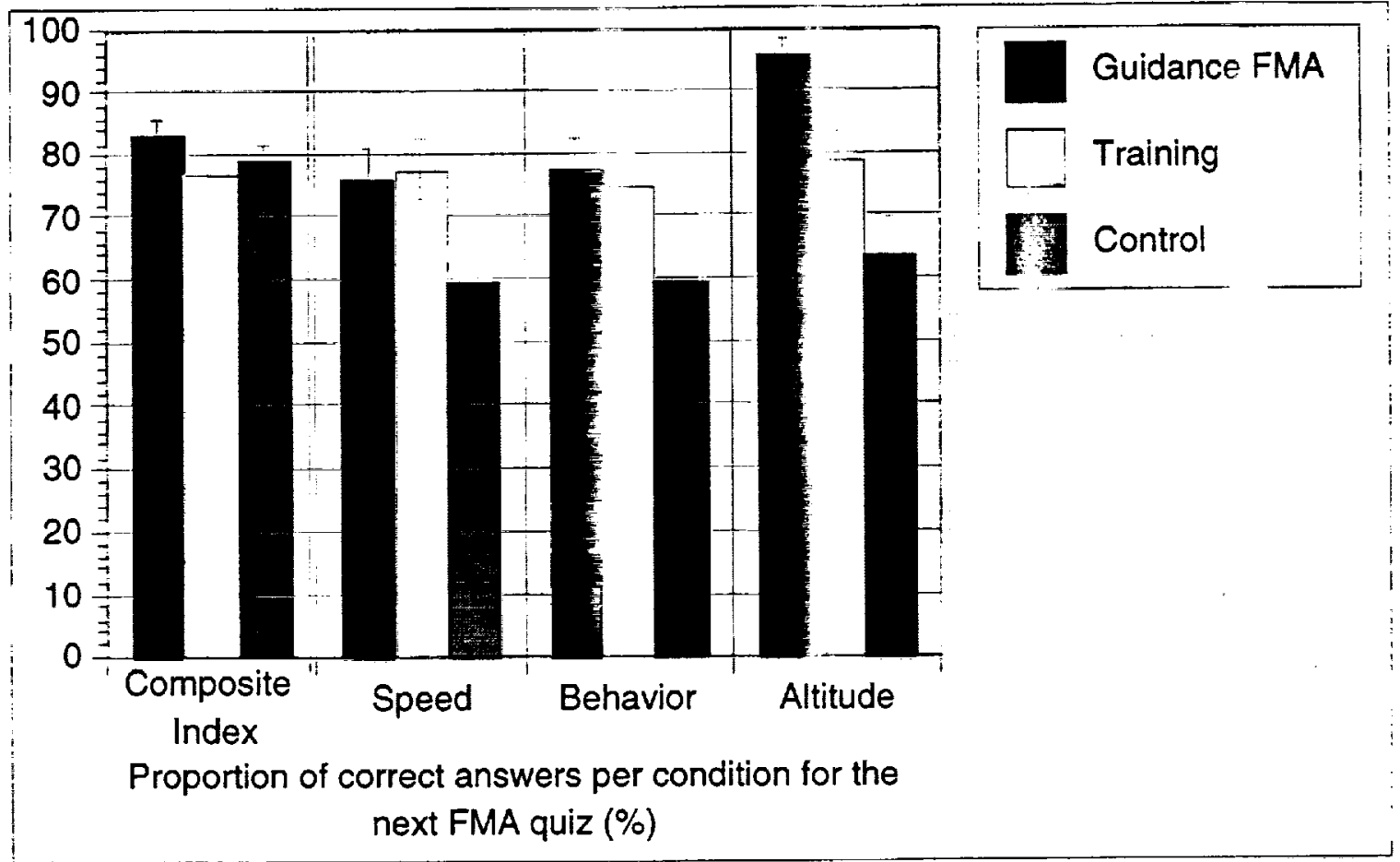

Figure 9. Results on flight quiz for future situation.

\section{Display Ratings}

We asked pilots in the display condition to rate the G-FMA in comparison with the existing FMA on MD- 11 s on seven rating scales. For each question, a five-point scale was used. Results indicated an overwhelming acceptance of the new display. Pilots felt the information was directly usable, helped them to understand the current modes, and helped them to feel more confident about what the avionics were doing. Most pilots reported that they would like to see the G-FMA on the MD-11.

We also asked pilots to provide comments on their experience with the G-FMA. Pilots reported that they felt a bit uncomfortable with removing thrust and pitch from the speed FMA. One pilot responded that the words used were not intuitive. All of the other comments were positive (see Appendix $F$ for a complete summary of the data).

\section{Simulation Comments}

Participants were asked to provide comments on the simulation and the fidelity of the simulation. Most felt that it was realistic and that the flight was representative of the flight in an airplane with regard to the displays and controls simulated. Pilots remarked that there was nothing quirky about the displays or the simulation that they felt would influence the study. 


\section{DISCUSSION OF EXPERIMENTAL RESULTS}

- G-FMA. The G-FMA emerged as the superior condition in this study. Looking at the objective data, we found that the pilots in the G-FMA condition could more accurately describe the current behavior and predict the next mode of operation than the pilots in the baseline group. Pilots in the G-FMA group were also better at constructing the next FMA when compared with the baseline group. The combination of training the pilot on what the vertical navigation system is doing and then displaying that information resulted in the best demonstration of pilot knowledge of the three groups. This may be a reflection of better understanding the avionics, more descriptive annunciation, or both, given the types of questions that were asked.

The data obtained from the subjective questionnaire showed that pilots liked the display and thought it was a useful device to have in the cockpit. Pilots stated that it was easier to understand what the airplane was doing and to predict what the next FMA would look like with the G-FMA. They also felt that the display was usable and made them more confident in their understanding of the avionics. The G-FMA was also thought to reduce automation surprises.

Pilots in the G-FMA condition had significantly fewer hours in the airplane than did pilots in both the training and baseline groups. This is an interesting finding because it indicates that we might have found even better understanding if we had equated the groups on experience. As one flies the airplane, one gains more experience with it and should understand better how it works than someone who has not flown as much. This finding also points to the need for having a G-FMA and advanced training available for pilots to get them up to speed and performing better with fewer hours in the airplane than pilots without this display and training combination.

- Training. The training condition gave more correct responses (when comparing means) than the baseline condition for all data collection metrics, but these were not significant differences at the 0.05 level. Under these conditions, we can only say that there was a trend for the training condition to be better than the baseline condition. In the subjective evaluation, pilots reported that they liked the tutor and that it presented the topics adequately, had an acceptable interaction, and had an acceptable speed of training delivery. A few negative comments were received, but these were from a minority of pilots in each case. These pilots pointed out that the displays were cluttered, lacked enough color coding, lacked feedback, and provided a poor overall leaming experience. Again, in each of these critical areas, there were significantly fewer pilots with complaints than those pilots who liked the tutor and found it valuable. To the overall question that asked for a rating of the tutor, responses were largely positive and pilots found the training program beneficial.

It is not clear how much the training adds to pilot understanding of the avionics from the current experiment. As we mentioned before, there were trends toward the training being a positive influence, but this was not statistically significant as calculated with post hoc pairwise comparison tests. For each of the measures of understanding, the display group was significantly better, with the training group having a higher, but not significantly different, mean from that of the baseline group. This indicates that both are necessary to really make an impact on the pilot. It is not enough 
to train pilots just in the operation of the airplane, they must also have a display that relates this knowledge back to the task.

- G-FMA and Training. In the display condition, pilots understood the workings of the airplane at a much higher level. We also found that this understanding applied to future understanding of airplane states. This is an extremely powerful combination and one that can lead to improved understanding on the part of the pilots. This understanding also can be obtained earlier in the learning curve for the airplane.

The findings also help the pilot to better understand the three questions posed by Wiener (1989): "What is it doing?", "Why did it do that?", and "What will it do next?" These three questions were the most frequent that were heard in glass cockpits by pilots trying to figure out how the avionics were operating. The first question relates to the present condition of the airplane, the second to how it got into that condition, and the third to a future state of flight. Our study showed that by training pilots and giving them the G-FMA, they were better able to answer these questions. The more knowledge that pilots have about the avionics, the less chance for an automation surprise, and there is a greater chance for the pilots to feel that they understand what is happening at all times and to be comfortable with the monitoring task that they are performing in automatic flight options.

- Speed on Thrust and on Pitch. Several pilots commented that they did not feel comfortable with our design solution to remove the speed mode that is presented on the original MD-11 FMA. Pilots use this information to understand how their speed is being controlled at different points in time. This is something that could be added to a future redesign of the G-FMA. We had originally removed this information because it is contained in the behavior label, but the speed mode could be easily added to the G-FMA with a minor realignment of the data fields (see Appendix $G$, where the intentional display is discussed).

\section{Possible Limitations}

One of the limitations of the study was that the tasks for the pilots in the G-FMA condition were easier than the other conditions and this task tracked directly to the data collection sheets. Pilots in the G-FMA task had to tell us what the next FMA was going to look like. In this case, they only needed to figure out the next operational procedure and put this in the window of the FMA template. In the other two conditions, pilots had to determine both the speed and pitch modes and select the appropriate words to describe these modes in the FMA template. The first task is inherently simpler because there is only one mode to select and it is a much more intuitive label to the pilot because it is more of an English-language descriptor of what the airplane will do in the next few minutes. The operational procedure names were also used on the data collection forms, which could have made this task easier for the G-FMA group. In the training and baseline groups, pilots had to mentally translate what the regular FMA was telling them and convert that to an operational procedure label for the behavior.

A second type of limitation for this study was the sample size used. We had 27 pilots in three conditions, which doesn't really provide a large amount of statistical power to reject false null hypotheses. 
This was evident in this study because we had so many trends when comparing the training group with the baseline group. Perhaps with more participants, this trend would have become a main effect.

\section{FOLLOW-UP RESEARCH NEEDS}

There are three areas where we feel we could improve on the current study and follow up this effort with other research.

- We would like to extend this study to take the G-FMA and integrate this with the white, or pilotinitiated, modes of operation. The present study asked pilots to keep the simulation in PROF, or fully automatic operation, for as much time as possible. The hybrid modes, however, are somewhat more troublesome for pilots because they have to understand what component of the cockpit system is controlling each of the flying functions. We need to integrate the display so that it is more fully functional in the hybrid modes to see if there are ways to improve on these annunciations and training.

- We could do a follow-on study in an actual simulator with visuals and flight motion to see how the new display and training interact with the entire flight. This would add to the realism of the study and would help to verify whether the G-FMA and training help in the full flight environment.

- We could include additional part-task studies, such as reaction time experiments, which could be useful in determining the advantages and disadvantages of the G-FMA in the flight environment.

\section{CONCLUSIONS}

Using the actual behavior of the avionics to design pilot training and displays is feasible and yields better pilot performance.

When PROF is engaged, the display of the guidance mode and targets yields improved pilot performance. 


\section{APPENDIX A-QUESTIONNAIRE}

\section{MD-11 Vertical Guidance Survey}

\section{Dear MD-11 Pilot:}

We are conducting a research project that is examining how pilots fly the MD-11 with full automation. We are asking all Fed Ex MD-11 pilots to help us to understand how they use PROF, how they feel the training prepared them for the MD-11 automation, and if they have been surprised by the automation. We are looking at ways to improve training and possibly redesign your displays to make them more "user friendly."

As with all research using human participants, we will protect your identity and the answers that you provide in several ways. All of the forms that are returned to us will be coded and entered into a database without names attached. The actual forms will be shredded soon after the database is created. Finally, all results will be reported as grouped data, no individual results will be reported.

If you have any comments or would like to relate specific instances of problems that you may have on a regular basis, please fill out the Comments section at the end of the survey.

Please return this survey in the postage-paid envelope or mail it to:

Daniel McCrobie

Human Factors Research Group

Honeywell, Inc.

PO Box 21111 - Mail Code: 2P36D2

Phoenix AZ 85036

If you have any questions about this survey, call Daniel at (602) 436-3604 or send an e-mail with your question to dan.mccrobie@cas.honeywell.com.

Thank you in advance for your helpful participation,

The VNAV Research Team,

Daniel McCrobie - Honeywell Human Factors Group

Lance Sherry - Honeywell Systems Integration Group

Jerry Kelly - Honeywell Systems Integration Group

Peter Polson - University of Colorado, Cognitive Science Department

Michael Feary - San Jose State University, Human Factors Department

Everett Palmer - NASA Ames Research Center, Human Factors Group

Please use your experience in the MD-11 to answer the following questions. For each question, fill in the blanks or circle the option that best describes your experiences. 


\section{Your Background}

1. When did you receive your MD-11 type rating?

3 months 6 months 1 year 2 years 3 or more years

2. Where did you do your ground school training?

MEM LGB Other:

3. Where did you do your simulator training?

MEM LGB HEL ZRH Other:

4. What was your previous seat position with FedEx and in which airplane?

Captain First Officer Second Officer

B-727 A-300 DC-10 B-747 Other:

5. How long were you in this previous seat position?

Less than 1 year $1-2$ years $2-3$ years $3+$ years

6. What is the majority of your previous flying background? Civilian Military

7. What other "glass cockpit" aircraft have you flown?

None or List:

8. Your approximate total MD-11 time:

Less than 100 hours Less than 500 hours Less than 1000 hours $1000+$ hours

9. Your approximate total fixed wing time:

Less than 2000 hours $\quad 2000-4000$ hours $\quad 4000-7000$ hours $\quad 7000+$ hours

10. Your age: Less than 30 years $\quad 31-40$ years $\quad 41-50$ years $50-59$ years

11. Your current MD-11 seat position:

Captain First Officer Flex Instructor Flight Standards Other: 


\section{Your Use of the MD-11 Automation}

1. For the climb phase of flight, I use PROF:
Always
Usually
Occasionally
Seldom Never

2. For the approach phase of flight, I use PROF:
Always
Usually
Occasionally
Seldom Never

3. For the descent phase of flight, I use PROF:

Always Usually Occasionally Seldom Never

4. I input winds and temperature on the Descent Forecast page:

Always Usually Occasionally Seldom Never

5. I edit the Flight Plan page to make it look like what I will fly on the approach:

Always Usually Occasionally Seldom Never

6. I use the DIR-TO page with course intercept $(\mathrm{XXX})$ when vectored to final approach:

Always Usually Occasionally Seldom Never

7. When building an approach, I erase the turn point or present position (PPOS):

Always Usually Occasionally Seldom Never

Flight Mode Annunciator (FMA) and Display Symbology

1. I use the FMA to determine what the vertical guidance is doing (i.e., PROF, PITCH, THRUST):

Always Usually Occasionally Seldom Never

2. I use the symbology on the Navigation Display (ND) to monitor where I am on the vertical path:

Always Usually Occasionally Seldom Never

3. I use the symbology on the PFD Speed Tape to determine what speed is commanded by FMS Speed:

Always Usually Occasionally Seldom Never


4. I use the symbology on the PFD Altitude Tape to determine what altitudes are being commanded by PROF:
Always
Usually
Occasionally
Seldom Never

5. I use the information on the FLT PLN page to determine the planned vertical path:
Always
Usually
Occasionally
Seldom Never

\section{Automation Surprises}

An "Automation Surprise" occurs when the automation commands a maneuver that the pilot is not expecting. Please tell us if you have ever experienced the following automation surprises in the MD-11.

1. Unable to make altitude crossing restrictions in descent:
Always
Usually
Occasionally
Seldom
Never

2. Unexplained "ALT ERROR AT XXX" message:
Always
Usually
Occasionally
Seldom
Never

3. Starting down too early (i.e. before reaching Top of Descent):
Always
Usually
Occasionally
Seldom
Never

4. Abrupt pitch changes:
Always Usually
Occasionally
Seldom Never

5. Lack of smoothness:

Always Usually Occasionally Seldom Never

6. Unexplained "ADD DRAG" or "REMOVE DRAG" messages:

Always Usually Occasionally Seldom Never

7. Decelerations commanded too early:
Always
Usually
Occasionally
Seldom
Never

8. Decelerations commanded too late:

Always Usually Occasionally Seldom Never 
9. Descent below charted altitude restriction in approach:
Alway
Usually
Occasionally
Seldom
Never

10. Unpredictable waypoint sequencing:
Always
Usually
Occasionally
Seldom
Never

11. Unpredictable speed targets during descent:
Always
Usually
Occasionally
Seldom
Never

12. Unpredictable speed targets during approach:
Always
Usually
Occasionally
Seldom Never

13. Unexpected level-offs:
Always Usually
Occasionally Seldom
Never

\section{Training Topics}

Please tell us which of the following topics you think should be covered in training. If you feel they are adequately covered, circle "No Further Training." If you feel that more training is needed on this topic, tell us whether it should be done in initial or recurrent training by circling either one of those words.

1. Additional training on how to better interpret the FMA displays:

No Further Training Initial Recurrent

2. Additional training on how to better interpret the PFD symbology:

No Further Training Initial Recurrent

3. Additional training on how to better interpret the ND symbology:

No Further Training Initial Recurrent

4. Additional training on how to interpret waypoint information on the FLT PLN page:

No Further Training Initial Recurrent

5. Using higher levels of automation (i.e., PROF, FMS SPD):

No Further Training Initial Recurrent 
6. Understanding how PROF works during descents:

No Further Training Initial Recurrent

7. Setting up the FLT PLN page for optimum vertical navigation:

No Further Training Initial Recurrent

8. FMS Speed logic in deceleration during descent and approach:

No Further Training Initial Recurrent

9. After your initial training, how long did it take you to feel comfortable with the level of automation that you use currently?

6 months 1 year Other__ Still not comfortable

Thank you for your help in filling out this survey.

Please feel free to add additional comments on the next page and on the back of the form. 


\section{Comments}

Use of PROF:

FMA's and Symbology:

Automation Surprises:

Training Topics: 
APPENDIX B-RESPONSES FROM THE QUESTIONNAIRE

\author{
Summary Tables for the Questionnaire Data
}

Table B-1. Percentages of Pilots who Reported Using PROF

\begin{tabular}{|l|c|c|c|c|}
\hline \multicolumn{1}{|c|}{ Phase of Flight } & Always & Usually & Occasionally & Seldom/Never \\
\hline \hline Climb & 73 & 25 & 2 & 1 \\
\hline Descent & 20 & 71 & 7 & 2 \\
\hline Approach & 5 & 26 & 27 & 41 \\
\hline
\end{tabular}

Table B-2. Percentages of Pilots who Reported Modifying Aspects of the Flight Plan

\begin{tabular}{|l|c|c|c|c|}
\hline \multicolumn{1}{|c|}{$\begin{array}{c}\text { Phase of } \\
\text { Flight/Modification }\end{array}$} & Always & Usually & Occasionally & Seldom/Never \\
\hline \hline $\begin{array}{l}\text { Erase turn-points or } \\
\text { positions }\end{array}$ & 20 & 56 & 16 & 9 \\
\hline Use direct intercept function & 11 & 40 & 27 & 23 \\
\hline Edit Flight Plan page & 59 & 35 & 3 & 3 \\
\hline $\begin{array}{l}\text { Input winds and } \\
\text { temperatures }\end{array}$ & 28 & 28 & 20 & 24 \\
\hline
\end{tabular}

Table B-3. Percentages of Pilots who Reported Using Displays for Surveillance

\begin{tabular}{|l|l|c|c|c|c|}
\hline \multicolumn{1}{|c|}{ Display Used } & \multicolumn{1}{|c|}{ To Monitor } & Always & Usually & Occasionally & Seldom \\
\hline \hline $\begin{array}{l}\text { Flight Mode } \\
\text { Annunciation }\end{array}$ & Vertical Guidance & 59 & 34 & 6 & 2 \\
\hline Navigation Display & $\begin{array}{l}\text { Position on Vertical } \\
\text { Path }\end{array}$ & 37 & 52 & 10 & 1 \\
\hline Speed Tape & Speed Commanded & 64 & 34 & 3 & 0 \\
\hline Altitude Tape & Altitude Commanded & 58 & 36 & 4 & 3 \\
\hline Flight Plan Page & Vertical Guidance & 28 & 47 & 19 & 7 \\
\hline
\end{tabular}


Table B-4. Percentages of Pilots who Reported Experiencing Automation Surprises

\begin{tabular}{|l|c|c|c|c|c|}
\hline \multicolumn{1}{|c|}{ Phase of Flight/Modification } & Always & Usually & Occas. & Seldom & Never \\
\hline \hline $\begin{array}{l}\text { Fail to make altitude } \\
\text { restrictions }\end{array}$ & 1 & 5 & 37 & 47 & 11 \\
\hline Unexplained altitude errors & 0 & 3 & 55 & 32 & 10 \\
\hline Airplane starts down too early & 1 & 2 & 11 & 37 & 48 \\
\hline Abrupt pitch changes & 0 & 0 & 7 & 35 & 57 \\
\hline Lack of smoothness & 0 & 2 & 15 & 44 & 39 \\
\hline Unexpected messages & 0 & 1 & 38 & 46 & 15 \\
\hline Deceleration too early & 10 & 34 & 34 & 16 & 6 \\
\hline Deceleration too late & 0 & 1 & 14 & 55 & 31 \\
\hline Descent below alt. restrictions & 0 & 0 & 1 & 21 & 77 \\
\hline $\begin{array}{l}\text { Unpredictable waypoint } \\
\text { sequencing }\end{array}$ & 1 & 0 & 4 & 35 & 62 \\
\hline $\begin{array}{l}\text { Unpredictable speed targets } \\
\text { during descent }\end{array}$ & 1 & 9 & 37 & 39 & 13 \\
\hline $\begin{array}{l}\text { Unpredictable speed targets } \\
\text { during approach }\end{array}$ & 2 & 14 & 40 & 27 & 17 \\
\hline Unexpected level-offs & 0 & 1 & 3 & 38 & 56 \\
\hline
\end{tabular}

Table B-5. Percentages of Pilots who wanted Specific Training

\begin{tabular}{|l|c|c|c|}
\hline \multicolumn{1}{|c|}{ Training Topic } & No Further & Initial & Recurrent \\
\hline \hline How to better interpret the Flight Mode Annunciator & 23 & 51 & 25 \\
\hline $\begin{array}{l}\text { How to better interpret the Primary Flight Display } \\
\text { symbology }\end{array}$ & 43 & 42 & 16 \\
\hline How to better interpret the NAV Display symbology & 44 & 39 & 16 \\
\hline How to interpret waypoint information on the FLT PLN page & 47 & 33 & 20 \\
\hline Using higher levels of automation (e.g. PROF, FMS SPD) & 27 & 27 & 46 \\
\hline Understanding how PROF works during descents & 17 & 49 & 34 \\
\hline $\begin{array}{l}\text { Setting up the FLT PLN page for optimum vertical } \\
\text { navigation }\end{array}$ & 24 & 36 & 40 \\
\hline $\begin{array}{l}\text { FMS Speed logic in deceleration during descent and } \\
\text { approach }\end{array}$ & 8 & 48 & 44 \\
\hline
\end{tabular}




\section{Demographic Items}

These questions asked for background information about the pilot's training, their hours on the MD-11, and what previous planes they have flown. Additionally, we asked for the respondent's age to complete the demographic picture of the pilots.

1. When did you receive your MD-11 type rating?

\begin{tabular}{cccccc} 
& 3 months & 6 months & 1 year & 2 years & 3 or more years \\
\hline Frequency & 20 & 34 & 45 & 18 & 86 \\
\hline Percentage & 10 & 17 & 22 & 9 & 43 \\
& & & Median $=4.0(2$ Years $)$
\end{tabular}

2. Where did you do your ground school training?

\begin{tabular}{cccc} 
& Memphis & Long Beach & Other \\
\hline Frequency & 134 & 56 & 13 \\
\hline Percentage & 66 & 28 & 6 \\
& \multicolumn{2}{c}{ Mode $=$ MEM }
\end{tabular}

Additional Comments:

Both MEM and LGB (2)

DFW, Dallas, or AA (13)

3. Where did you do your simulator training?

\begin{tabular}{cccccc} 
& Memphis & Long Beach & Helsinki & Zurich & Other \\
\hline Frequency & 157 & 27 & 15 & 3 & 1 \\
\hline Percentage & 77 & 14 & 7 & 15 & 1
\end{tabular}

Additional Comments:

Both LGB and MEM

Both MEM and ZRH

Initial FO done in MEM, upgrade to Captain at London Gatewick (Formerly owned by Hughes) 
4a. What was your previous seat position with FedEx and in which airplane?

\begin{tabular}{cccc} 
& Captain & First Officer & Second Officer \\
\hline Frequency & 68 & 65 & 66 \\
\hline Percentage & 34 & 32 & 33 \\
& Mode $=$ Captain & Missing $=4$ &
\end{tabular}

4b. What was your previous seat position with FedEx and in which airplane?

\begin{tabular}{cccccc} 
& B-727 & A-300 & DC-10 & B-747 & Other \\
\hline Frequency & 95 & 8 & 56 & 40 & 4 \\
\hline Percentage & 47 & 4 & 28 & 20 & 2 \\
& & & Mode $=$ B-727 & &
\end{tabular}

Additional Comments:

Second Officer on 727

DC-8

First Officer on MD-11 (2)

B 727, before that KC-10

DC-10 First Officer

Ex Flying Tiger

B-727 and A300

5. How long were you in this previous seat position?

\begin{tabular}{ccccc} 
& Less than 1 year & $1-2$ years & $2-3$ years & More than 3 years \\
\hline Frequency & 33 & 36 & 40 & 94 \\
\hline Percentage & 17 & 18 & 20 & 46 \\
& & Median $=3.0(2-3$ years $)$
\end{tabular}

Additional Comments:

DC-10 Captain for eight years prior to 747

6. What is the majority of your previous flying background?

\begin{tabular}{ccc} 
& Civilian & Military \\
\hline Frequency & 101 & 102 \\
\hline Percentage & 50 & 50 \\
& Mode $=$ Civilian &
\end{tabular}

Additional Comments:

About equal time in each (50/50) (4 responses) 
7. What other "glass cockpit" aircraft have you flown?

\begin{tabular}{ccc} 
& None & Listed another glass cockpit \\
\hline Frequency & 156 & 46 \\
\hline Percentage & 77 & 23 \\
Mode = None (No other glass cockpits flown) & Missing = 1
\end{tabular}

Additional Comments:

\begin{tabular}{llll}
$757(4)$ & SF-340 (2) & A300/310 (7) & \multicolumn{2}{l}{ DC-8-72Beechjet 400A } \\
$767(1)$ & F-14 (3) & A-300 (3) & Collins EFIS G-II \\
EMB 120 & DHC-8-300 & F/A-18 (3) & MD-80 \\
A-6 & Dornier 328 & Gulfstream IV (3) & AV-8B \\
F-16 (9) & CE-650 & F-111 & F-15 \\
\hline
\end{tabular}

8. Your approximate total MD-11 time:

\begin{tabular}{lcccc} 
& $<100 \mathrm{hr}$ & $<500 \mathrm{hr}$ & $<1000 \mathrm{hr}$ & $>1000 \mathrm{hr}$ \\
\hline Frequency & 16 & 58 & 37 & 91 \\
\hline Percentage & 8 & 28 & 19 & 45 \\
& Median $=3$ (Between 500 and 1000 hours)
\end{tabular}

Additional Comments:

3,000 hours (2)

140 hours

9. Your approximate total fixed wing time:

\begin{tabular}{ccccc} 
& $<2000 \mathrm{hr}$ & $2000-4000 \mathrm{hr}$ & $4000-7000 \mathrm{hr}$ & $>7000 \mathrm{hr}$ \\
\hline Frequency & 1 & 22 & 49 & 131 \\
\hline Percentage & 1 & 11 & 24 & 65 \\
& \multicolumn{4}{c}{ Median $=4$ (More than 7000 hours) }
\end{tabular}

Additional Comments:

16,000 hours 
10. Your age:

\begin{tabular}{lcccc} 
& Less than 30 years & $31-40$ years & $41-50$ years & $50-59$ years \\
\hline Frequency & 2 & 50 & 94 & 57 \\
\hline Percentage & 1 & 25 & 47 & 28 \\
& \multicolumn{2}{c}{ Median $=3(41$ to 50 years old $)$}
\end{tabular}

11. Your current MD-11 seat position:

\begin{tabular}{ccccc} 
& Captain & First Officer & Flex Instructor & Flight Standards \\
\hline Frequency & 88 & 103 & 9 & 3 \\
\hline Percentage & 44 & 50 & 5 & 2 \\
& & Mode = First Officer
\end{tabular}

Additional Comments:

First Officer in upgrade to Captain (2)

\section{Use of the MD-11 Automation}

This set of questions asked the pilot to tell us how they normally flew the plane in terms of procedures followed and use of PROF or full automatic mode. Note that FedEx procedure is for the pilot to keep the airplane in PROF mode for as long as possible throughout the flight.

1. For the climb phase of flight, I use PROF:

$$
\text { Always (1) Usually (2) Occasionally (3) Seldom (4) Never (5) }
$$

\begin{tabular}{cccccc}
\hline Frequency & 148 & 50 & 3 & 2 & 0 \\
\hline Percentage & 73 & 25 & 2 & 1 & 0 \\
& & & Mean $=1.31$ & &
\end{tabular}

Additional Comments:

Acceleration at 10,000 feet is not efficient. I usually over-ride the system with vertical climb until the trend line reach the desired airspeed, then go back to PROF again. 
2. For the approach phase of flight, I use PROF:

\begin{tabular}{cccccc} 
& Always (1) & Usually (2) & Occasionally (3) & Seldom (4) & Never (5) \\
\hline Frequency & 10 & 53 & 54 & 60 & 26 \\
\hline Percentage & 5 & 26 & 27 & 28 & 13 \\
& & & Mean $=3.19$ &
\end{tabular}

Additional Comments:

Except for FMS Speed

Until Final

Almost Always

At LAX CIVIT arrival

3. For the descent phase of flight, I use PROF:

\begin{tabular}{ccccccc} 
& Always (1) & Usually (2) & Occasionally (3) & Seldom (4) & Never (5) \\
\hline Frequency & 41 & 145 & 14 & 1 & 2 \\
\hline Percentage & 20 & 71 & 7 & 1 & 1 \\
& & \multicolumn{2}{c}{ Mean $=1.91$}
\end{tabular}

Additional Comments:

Until I am below 10,000 feet, then I use manual speed select.

Usually until I get tired or seeing poor adherence to airspeed control, then I go to V/S.

4. I input winds and temperature on the Descent Forecast page:

\begin{tabular}{ccccccc} 
& Always (1) & Usually (2) & Occasionally (3) & Seldom (4) & Never (5) \\
\hline Frequency & 56 & 59 & 41 & 30 & 17 \\
\hline Percentage & 28 & 28 & 20 & 15 & 9 \\
& & \multicolumn{2}{c}{ Mean $=2.48$} &
\end{tabular}

Additional Comments:

I have captains discourage me from any wind inputs.

Did it for a while but I can't tell the difference.

I don't do this because the system isn't good enough to make use of these data. Data from ATIS is not

available until the high workload phase has begun.

The old 3 miles $/ 1000$ feet and idle thrust is just as good.

If the MD-11 knows the current winds (IRS), why do I have to type in the descent winds? 
5. I edit the Flight Plan page to make it look like what I will fly on the approach:

\begin{tabular}{ccccccc} 
& Always (1) & Usually (2) & Occasionally (3) & Seldom (4) & Never (5) \\
\hline Frequency & 119 & 72 & 7 & 3 & 2 \\
\hline Percentage & 59 & 35 & 3 & 2 & 1 \\
& & \multicolumn{2}{c}{ Mean $=1.52$}
\end{tabular}

Additional Comments:

If I know in advance.

I like to use this feature, however, it is tough to get the other guy to program the box or he will say, "We are too close, forget it."

Or, I use the DIR TO and clear the turn point.

6. I use the DIR-TO page with course intercept $(\mathrm{XXX})$ when vectored to final approach:

\begin{tabular}{ccccccc} 
& Always (1) & Usually (2) & Occasionally (3) & Seldom (4) & Never (5) \\
\hline Frequency & 21 & 82 & 54 & 34 & 12 \\
\hline Percentage & 11 & 40 & 27 & 17 & 6 \\
& & \multicolumn{2}{c}{ Mean $=2.68$} &
\end{tabular}

Additional Comments:

Usually, I just push APPROACH/LAND when cleared to the intercept.

If the intercept angle is greater than 30 degrees.

Almost always unless I can get the PNF to do it or if he can't.

DIR TO and clear turn point is easier and provides the same guidance.

I always use it.

At 36C MEM, after you have built an approach going DIR TO Koley and Clian, the same Koley will get you the same centerline extension from Koley.

7. When building an approach, I erase the turn point or present position (PPOS):

\begin{tabular}{cccccc} 
& Always (1) & Usually (2) & Occasionally (3) & Seldom (4) & Never (5) \\
\hline Frequency & 40 & 113 & 31 & 14 & 4 \\
\hline Percentage & 20 & 56 & 16 & 7 & 2 \\
& & Mean $=2.16$ & Missing $=1$ & &
\end{tabular}

Additional Comments:

This messes up the distance read out on the NAV display.

Unless you mean when vectored, then always.

When being vectored in the terminal area. 


\section{FMA and Display Symbology}

This set of questions asked pilots to rate how they use the current FMA and symbology to fly the airplane. It also questions how they use specific symbology in relation to FMA annunciations to determine what the system is doing at a given time.

1. I use the FMA to determine what the vertical guidance is doing (i.e., PROF, PITCH, THRUST):

\begin{tabular}{cccccc} 
& Always (1) & Usually (2) & Occasionally (3) & Seldom (4) & Never (5) \\
\hline Frequency & 117 & 70 & 13 & 1 & 1 \\
\hline Percentage & 59 & 34 & 6 & 1 & 1 \\
& & Mean $=1.50$ & Missing $=1$ & &
\end{tabular}

Additional Comments:

At 10,000 feet, I go to V/S to accelerate to en route climb speed faster.

If I can remember to look after I select it.

2. I use the symbology on the Navigation Display (ND) to monitor where I am on the vertical path:

Always (1) Usually (2) Occasionally (3) Seldom (4) Never (5)

\begin{tabular}{cccccc} 
& Always (1) & Usually (2) & Occasionally (3) & Seldom (4) & Never (5) \\
\hline Frequency & 74 & 107 & 19 & 2 & 0 \\
\hline Percentage & 37 & 52 & 10 & 1 & 0 \\
& & Mean $=1.75$ & Missing $=1$ & &
\end{tabular}

Additional Comments:

Taking into account what's programmed for the approach.

Sometimes I use PERF.

With the PERF Descent page always (one or the other).

Plus a quick look at the PERF page during descent when the diamond is pegged.

ATC speed restraints dictate different air speeds.

I use the PERF page on the CDU during descent. 
3. I use the symbology on the PFD Speed Tape to determine what speed is commanded by FMS Speed:

\begin{tabular}{ccccccc} 
& Always (1) & Usually (2) & Occasionally (3) & Seldom (4) & Never (5) \\
\hline Frequency & 128 & 70 & 5 & 0 & 0 \\
\hline Percentage & 64 & 34 & 3 & 0 & 0 \\
& & & Mean $=1.39$
\end{tabular}

Additional Comments:

Boy is it screwed up!

Speeds are sometimes random.

Occasionally at 12,500 feet, I select airspeed hold 320 to keep PROF from commanding speed reduction to 245 knots. This causes "Speed limit Exceeded" alert which goes away when PROF speed is selected at 10,000 feet.

4. I use the symbology on the PFD Altitude Tape to determine what altitudes are being commanded by PROF:

Always (1) Usually (2) Occasionally (3) Seldom (4) Never (5)

\begin{tabular}{cccccc}
\hline Frequency & 116 & 74 & 8 & 5 & 0 \\
\hline Percentage & 58 & 36 & 4 & 3 & 0 \\
& & & Mean $=1.51$ & &
\end{tabular}

5. I use the information on the FLT PLN page to determine the planned vertical path:

\begin{tabular}{ccccccc} 
& Always (1) & Usually (2) & Occasionally (3) & Seldom (4) & Never (5) \\
\hline Frequency & 55 & 95 & 39 & 12 & 2 \\
\hline Percentage & 28 & 47 & 19 & 6 & 1
\end{tabular}

Additional Comments:

PERF Page is used. 


\section{Automation Surprises}

An "Automation Surprise" occurs when the automation commands a maneuver that the pilot is not expecting. We asked pilots if they had ever experienced the following "automation surprises" in the MD-11.

1. Unable to make altitude crossing restrictions in descent:

\begin{tabular}{cccccc} 
& Always (1) & Usually (2) & Occasionally (3) & Seldom (4) & Never (5) \\
\hline Frequency & 1 & 9 & 75 & 95 & 21 \\
\hline Percentage & 1 & 5 & 37 & 47 & 11 \\
& & Mean $=3.63$ & . Missing $=2$ & &
\end{tabular}

Additional Comments:

Note small experience level, I have only shot 25 approaches and it is difficult to be surprised too much.

Never, if programmed correctly.

Some aircraft are slow in vertical profile corrections.

Occasionally you have to keep up on it, for example with speed brakes.

2. Unexplained "ALT ERROR AT XXX" message:

\begin{tabular}{cccccc} 
& Always (1) & Usually (2) & Occasionally (3) & Seldom (4) & Never (5) \\
\hline Frequency & 0 & 6 & 111 & 65 & 20 \\
\hline Percentage & 0 & 3 & 55 & 32 & 10 \\
& & Mean $=3.50$ & Missing $=1$ & &
\end{tabular}

Additional Comments:

Usually during approach phase.

3. Starting down too early (i.e., before reaching Top of Descent):

\begin{tabular}{cccccc} 
& Always (1) & Usually (2) & Occasionally (3) & Seldom (4) & Never (5) \\
\hline Frequency & 2 & 5 & 22 & 75 & 96 \\
\hline Percentage & 1 & 2 & 11 & 37 & 48 \\
& & Mean $=4.30$ & Missing $=3$ & &
\end{tabular}

Additional Comments:

Although Top of Descent was too early.

No need to start down so early.

Slowdowns are usually our normal operations, I almost always do a level change instead of PROF in descent. 
4. Abrupt pitch changes:

Always (1) Usually (2) Occasionally (3) Seldom (4) Never (5)

\begin{tabular}{cccccc}
\hline Frequency & 0 & 0 & 15 & 69 & 116 \\
\hline Percentage & 0 & 0 & 7 & 35 & 57 \\
& & Mean $=4.51$ & Missing $=3$ & &
\end{tabular}

Additional Comments:

Usually on the ground at touchdown, never in the air.

Some aircraft have very rough pitch controllers.

5. Lack of smoothness:

\begin{tabular}{cccccc} 
& Always (1) & Usually (2) & Occasionally (3) & Seldom (4) & Never (5) \\
\hline Frequency & 0 & 4 & 30 & 88 & 80 \\
\hline Percentage & 0 & 2 & 15 & 44 & 39 \\
& & Mean $=4.22$ & Missing $=1$ & &
\end{tabular}

Additional Comments:

Slow to correct for incorrect descent rates.

Especially on non protected ILS approaches with wavering raw data. It's like being in a rowboat with three foot swells.

It is almost too smooth and deliberate.

6. Unexplained "ADD DRAG" or "REMOVE DRAG" messages:

\begin{tabular}{cccccc} 
& Always (1) & Usually (2) & Occasionally (3) & Seldom (4) & Never (5) \\
\hline Frequency & 0 & 2 & 76 & 92 & 31 \\
\hline Percentage & 0 & 1 & 38 & 46 & 15 \\
& & Mean $=3.76$ & Missing $=2$ & &
\end{tabular}

Additional Comments:

Sometimes as a result of using DIR INTC. 
7. Decelerations commanded too early:

Always (1) Usually (2) Occasionally (3) Seldom (4) Never (5)

\begin{tabular}{cccccc}
\hline Frequency & 20 & 70 & 70 & 31 & 12 \\
\hline Percentage & 10 & 34 & 34 & 16 & 6 \\
& & & Mean $=2.74$ &
\end{tabular}

Additional Comments:

Always when out approximately 13,000 feet and slowing down to 245 knots.

On Approach/Final.

The -910 software FOOT +5 at $13-14,000$ feet in descent.

From 11,000 to 10,000 feet with no speed restrictions. I have yet been able to edit the speed in PROF to maintain 350/320 without going manual.

Especially with -910 during approach. FOOT +5 is too slow.

I normally see the hollow speed ball drop down while on vectors to final at a speed of my choice or by ATC, so I can't answer questions 7 or 8 .

Descending through 12,500 feet en route to 10,000 feet.

This is due to a JAL or KAL mole in your software department. They always slow to $245 @ 50$ to 60 miles out.

8. Decelerations commanded too late:

\begin{tabular}{cccccc} 
& Always (1) & Usually (2) & Occasionally (3) & Seldom (4) & Never (5) \\
\hline Frequency & 0 & 2 & 27 & 110 & 63 \\
\hline Percentage & 0 & 1 & 14 & 55 & 31 \\
& & Mean $=4.15$ & Missing $=1$ & &
\end{tabular}

Additional Comments:

Seldom associated with descent.

9. Descent below charted altitude restriction in approach:

Always (1) Usually (2) Occasionally (3) Seldom (4) Never (5)

\begin{tabular}{cccccc}
\hline Frequency & 0 & 0 & 2 & 43 & 156 \\
\hline Percentage & 0 & 0 & 1 & 21 & 77 \\
& & Mean $=4.78$ & Missing $=2$ & &
\end{tabular}

Additional Comments:

Never, if entered correctly in the flight plan page. 
10. Unpredictable waypoint sequencing:

\begin{tabular}{cccccc} 
& Always (1) & Usually (2) & Occasionally (3) & Seldom (4) & Never (5) \\
\hline Frequency & 1 & 0 & 7 & 69 & 125 \\
\hline Percentage & 1 & 0 & 4 & 35 & 62 \\
& & Mean $=4.56$ & Missing $=1$ & &
\end{tabular}

Additional Comments:

Deletion of ABEAM points when DIR TO with ABEAMS was commanded.

Never the aircraft's fault. I've managed to mess it up myself.

Seldom with the -911 load.

11. Unpredictable speed targets during descent:

\begin{tabular}{cccccc} 
& Always (1) & Usually (2) & Occasionally (3) & Seldom (4) & Never (5) \\
\hline Frequency & 3 & 18 & 75 & 80 & 26 \\
\hline Percentage & 1 & 9 & 37 & 39 & 13 \\
& & Mean $=3.56$ & Missing $=1$ & &
\end{tabular}

Additional Comments:

From the teens to 10,000 foot level-off than in the App Program.

12. Unpredictable speed targets during approach:

\begin{tabular}{ccccccc} 
& Always (1) & Usually (2) & Occasionally (3) & Seldom (4) & Never (5) \\
\hline Frequency & 4 & 28 & 81 & 55 & 34 \\
\hline Percentage & 2 & 14 & 40 & 27 & 17 \\
& & Mean $=3.45$ & Missing $=1$ & &
\end{tabular}

Additional Comments:

The aircraft goes too fast or wants to go too fast in descent. It goes up into the high speed red speed bar. I see this often an it is my biggest objection to descent in PROF.

Occasionally-Generally when you have 28 Flaps and FMS speed, the V Ball and speeds are sometimes weird.

That's because we are macho, want to do speed selection, and we don't watch or use the FMS until it is dirty.

Occasionally after the FMS speed selection on Final with gear down and flaps at 35/50, I get a solid magenta

ball that jumps to a higher speed between 185 and 205 .

I have seen the FMS speed ball bounce between 245 knots and FMS speed.

Before Flaps 35 or 50 .

Wrong, but predictable.

Recently, I saw FOOT +25 knots with the flaps set at 35 . 
13. Unexpected level-offs:

\begin{tabular}{cccccc} 
& Always (1) & Usually (2) & Occasionally (3) & Seldom (4) & Never (5) \\
\hline Frequency & 0 & 1 & 12 & 76 & 113 \\
\hline Percentage & 0 & 1 & 3 & 38 & 56 \\
& & Mean $=4.48$ & Missing $=1$ & &
\end{tabular}

Additional Comments:

Usually this results from using DIR and NTC.

\section{Training Topics}

This last section asked pilots to determine whether a given topic should be covered in the training or learned on the line. If the topic was adequately covered, they responded with "No Further Training." If they felt that more training was needed on this topic, they told us whether it should be done in initial or recurrent training.

1. Additional training on how to better interpret the FMA displays:

\begin{tabular}{cccc} 
& No Further & Initial & Recurrent \\
\hline Frequency & 47 & 102 & 51 \\
\hline Percentage & 23 & 51 & 25 \\
& Mode $=$ Initial & Missing $=3$ &
\end{tabular}

Additional Comments:

Change the whole training to more classroom and less CMI.

Buy new MD-11 pilots both Honeywell manuals.

Screwy question. If it needs to be done in initial, it needs to be reinforced in recurrent, these are not mutually exclusive.

Especially speed on thrust versus speed on pitch.

Good review.

Do a better job.

Initial definitely. Recurrent good to do also.

Slow the simulator down at each phase of flight and point out what the FMA is telling us. I think this would enhance the FMA interpretation. 
2. Additional training on how to better interpret the PFD symbology:

\begin{tabular}{rccc} 
& No Further & Initial & Recurrent \\
\hline Frequency & 85 & 81 & 32 \\
\hline Percentage & 43 & 42 & 16 \\
Mode $=$ & No Further Training & Missing $=5$ &
\end{tabular}

Additional Comments:

We need flight safety feedback on instances that occur on the line. Discuss line operations that have occurred.

3. Additional training on how to better interpret the ND symbology:

\begin{tabular}{rccc} 
& No Further & Initial & Recurrent \\
\hline Frequency & 87 & 78 & 33 \\
\hline Percentage & 44 & 39 & 16 \\
Mode $=$ No Further Training & Missing $=5$ &
\end{tabular}

Additional Comments:

The symbols displayed on the MCDU, especially those that come up in the terminal arrival phase, are not explained in the flight manual.

4. Additional training on how to interpret waypoint information on the FLT PLN page:

\begin{tabular}{rccc} 
& No Further & Initial & Recurrent \\
\hline Frequency & 93 & 64 & 41 \\
\hline Percentage & 47 & 33 & 20 \\
Mode $=$ & No Further Training & Missing $=5$ &
\end{tabular}

5. Using higher levels of automation (i.e., PROF, FMS SPD):

\begin{tabular}{cccc} 
& No Further & Initial & Recurrent \\
\hline Frequency & 52 & 53 & 94 \\
\hline Percentage & 27 & 27 & 46 \\
& Mode $=$ Recurrent & Missing $=5$ &
\end{tabular}

Additional Comments:

When weather is windy in ANC or HKG, the automation is worthless. You need more physical transitions to severe runway wind and turbulence conditions.

It is critical at initial. The levels of automation and how to mix and match them must be emphasized and reviewed more. 
6. Understanding how PROF works during descents:

\begin{tabular}{cccc} 
& No Further & Initial & Recurrent \\
\hline Frequency & 35 & 97 & 67 \\
\hline Percentage & 17 & 49 & 34 \\
& Mode $=$ Initial & Missing $=4$ &
\end{tabular}

Additional Comments:

Sometimes it has a mind of its own. Usually it is not a fuel-efficient descent.

At initial it wouldn't hurt.

And the engine out profile at altitude.

How does it work during descent? I can't find any consistent logic behind it.

Or doesn't work.

7. Setting up the FLT PLN page for optimum vertical navigation:

\begin{tabular}{cccc} 
& No Further & Initial & Recurrent \\
\hline Frequency & 47 & 73 & 78 \\
\hline Percentage & 24 & 36 & 40 \\
& Mode $=$ Recurrent & Missing $=5$ &
\end{tabular}

Additional Comments:

At initial it wouldn't hurt.

Irrelevant unless I can understand what PROF is trying to do.

IOE (2)

8. FMS Speed logic in deceleration during descent and approach:

\begin{tabular}{cccc} 
& No Further & Initial & Recurrent \\
\hline Frequency & 15 & 96 & 88 \\
\hline Percentage & 8 & 48 & 44 \\
& Mode $=$ Initial & Missing $=3$ &
\end{tabular}

Additional Comments:

Is there logic there?

More advanced knowledge on this logic would be helpful.

What speed logic?

Don't use it.

IOE

At initial it wouldn't hurt.

New FMC -911 load

This lacks consistency in performance. I don't understand the speed logic on descent. 
9. After your initial training, how long did it take you to feel comfortable with the level of automation that you use currently?

\begin{tabular}{ccccc} 
& 6 months & 1 year & Other & Still not comfortable \\
\hline Frequency & 70 & 59 & 37 & 32 \\
\hline Percentage & 35 & 30 & 19 & 16 \\
& & Mode $=6$ months & Missing $=5$ &
\end{tabular}

Additional Comments:

I wouldn't use FMS speed or autothrottles if I wasn't required to do so.

I am still not comfortable with PROF descents. Both PROF and Speed are inconsistent from one flight to another.

These seem to be arbitrary.

But I learn something new on a continuous basis.

Comfortable but I do not trust it, particularly after a new load is installed.

I am comfortable with the aircraft and automation but I am still feeling like I am learning and improving every flight. The most uncomfortable phase is the last 200 feet in landing because I know the aircraft can bite me quickly and I don't get much practice at this phase.

Soon because of my Airbus FMS/Honeywell background.

I am still not comfortable. I felt better in IOE than now due to a lack of proficiency.

I am not comfortable trusting the system. This may be good because I don't become complacent.

I am still not comfortable and working on displays.

I am still very wary of this system, it seems as though there are booby traps out to get you when you let your guard down.

About 1 year, we don't fly much in the beginning.

After about 400 hours of flight.

I am too new to comment.

Not there yet at 50 hours and 6 landings.

Immediately.

One month (5).

One to two months (2).

Two months (4).

Two to three months (2).

Three months (4).

Four months.

Four to five months.

Less than six months (2).

Six months to a year.

Eight months and still learning.

Ten months.

Two years (2).

\section{Summary of Open-Ended Comments}

Additionally, pilots were asked to provide comments on four topics: use of automated vertical navigation, interpretation of the FMA, automation surprises, and training. For each category, between 45 and 80 pilots filled in comments on this last page of the questionnaire. The comments have been summarized under topic categories with the number of comments in this category following the short name of the topic. 
Use of PROF-There were the most comments provided in this topic area with 80 pilots providing one or several comments in this area. The responses were consolidated into the categories, although there were many more single comments that did not fall into a category. This method summarizes the thrust of the comments provided and attempts to capture the overall feeling of comments that were made in this category.

ATC (6) - The ATC system limits the use of PROF in descent. They vector the plane to a course and this requires pilots to come out of PROF and into a more hybrid automation.

Descent (21) - PROF is difficult to use when the plane was in descent less than 10,000 feet. Pilots also felt that the plane slows down too early in this mode.

Design (5) - These comments dealt with specific features that pilots liked or disliked about the logic and control design.

Good (16) - Pilots liked using PROF and thought that it was a great system.

Speed (7) - The speed control on the plane is confusing. Other comments in this section pointed to PROF being too conservative and this causes pilots to come out of PROF too early.

Training (6) - We are not adequately trained in PROF operation.

Trust (4) - Don't use PROF because it has let me down before and I do not trust it.

Usage (13) - Pilots reported that they felt that they needed experience to use PROF and feel comfortable with it. One pilot stated that you need at least 60 landings in the system to achieve proficiency. They also felt that there were many ways to improperly set up the system (pilot entered data) so that problems were created later in the flight.

Workload (2) - PROF can increase pilot workload in scanning because there are more data points to look at.

FMA and Symbology- There were 45 pilots responding in this category. The breakdown of comments is as follows:

Design (13) - Comments in this category requested additional symbology, changes to symbology and changes in the color scheme for information.

Good (10) - These pilots reported that they liked the current FMA and had no problems with it or symbology in general.

Training (11) - Pilots wanted an FMA trainer and more training in interpretation of the displays.

Understanding (2) - These comments focused on the length of time that it takes a pilot to learn the system symbols. One pilot suggested this was a six-month process. 
Usage (9) - Comments in this category include the observation that you have to look elsewhere besides the FMA to get the whole story of what is going on. Others thought that the FMA was too confusing.

Automation Surprises- 56 pilots provided comments on automation surprises. These responses were coded into categories based on the primary thrust of the pilot's response. Five categories were created with ten of the responses not fitting into one of the five categories. The categories, numbers of responses in each category, and a brief summary of the comments are provided below:

Approach (2) - Surprises always happen below 10,000 feet.

Design (9) - As the FMS product matures, there are fewer surprises. Pilots are unaware of the underlying "obscure logic" being used in the FMS. It was reported to be frustrating to enter waypoints and get error messages because they are too close to the airplane. Inserting approaches is not the same for different parts of the world. We are not given FMS conventions. Can drop out of PROF or NAV mode without a warning.

Experience (15) - Surprises come from not understanding the system. Many errors are pilot induced and these decrease with experience. When pilots don't know how the system works, it is easy to be surprised.

Speed (18) - The plane slows too early. FMS Speed mode causes surprises. This plane places a priority on airspeed over altitude, which is a problem when you have speed- and altitudeconstrained waypoints.

Trust (2) - Not confident that it will make altitude restrictions. I never trust the automation completely.

Training- 45 comments on training were collected in the following categories:

Additional (2) - Need more training on the FMS.

Aids (3) - Need learning aids to help teach and learn the system. Learning and refresher aids would be nice. A standard method for initial training was also suggested.

Basics (15) - Stick to a basic approach to training, teach the "must know" parts first, "should know parts second, and then go into "nice to know" aspects.

Design (2) - Use the Airbus design to simplify the system.

FMS Trainer (20) - Need an FMS trainer so that system pilots can use this on their own and get more hands-on training on the FMS.

Poor (3) - The training is poor and needs to be improved. 


\section{APPENDIX C-EXAMPLE OF THE TUTOR USED IN THE EXPERIMENT}

LATE DESCENT (1 of 5): Operation

LATE DESCENT is initiated when the airplane is more than $250 \mathrm{ft}$ above the reference altitude for that point along the optimum descent path It is indicated by magenta PITCH speed control and IDLE altitude control.
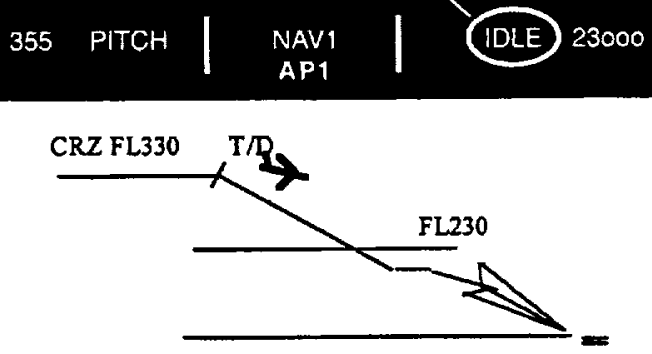

Click on the Path Indication on the Vertical deviation Indicator to continue.

LATE DESCENT (2 of 5): Speed Targes

In LATE DESCENT the aircraft will aggessively attempt to recapture the optimum descent path by using idle thrust and speed on pitch at speeds up to $\mathrm{Vmo} / \mathrm{Mmo}$ minus $10 \mathrm{kts}$.

\section{PTTCH 1 NAVI | TOLE 23000}
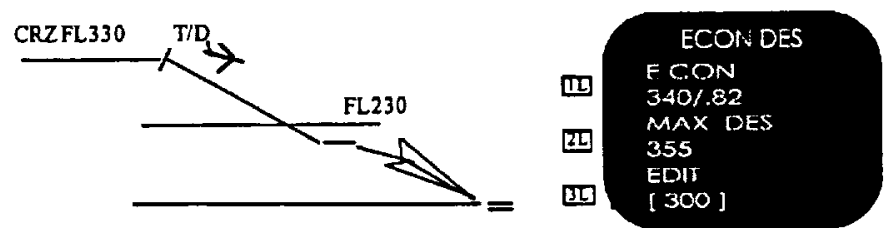

Click on the Path Indication on the Vertical deviation Indicator to continue. 
LATE DESCENT (3 of 5): Operation

Once the optimum descent path is recaptured, the aircraft will resume the PROF DESCENT.
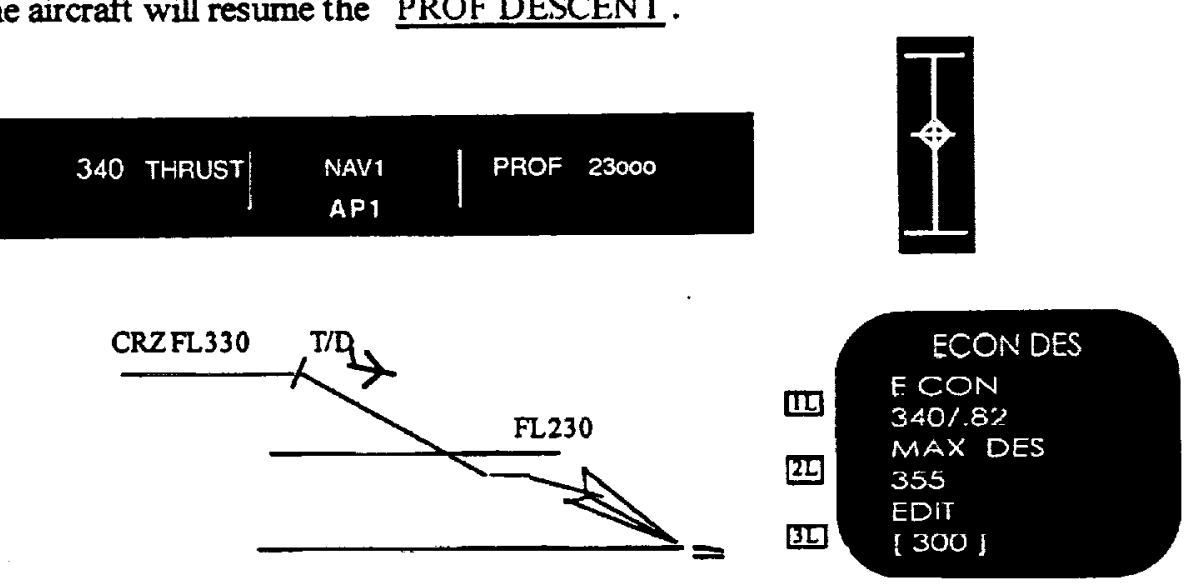

Click on the Altitude Control Mode on the FMA to cont inue.

LATE DESCENT (4 of 5): Operation

\section{The FMA for:}

\section{LATE DESCENT}

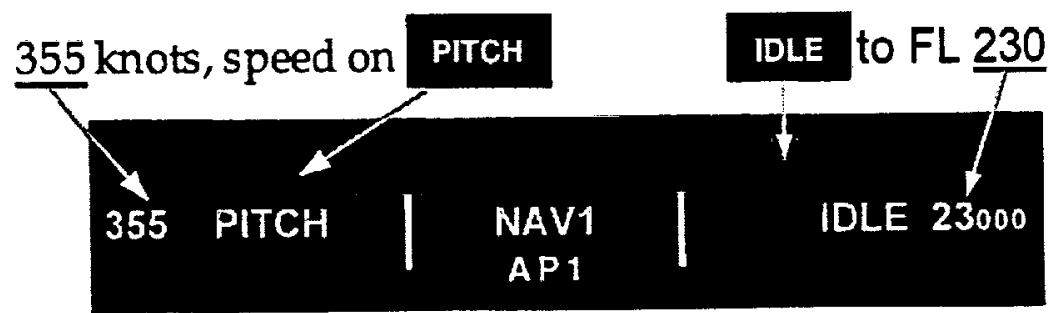

Refer to module 3 for questions about the altitude targets. 
LATEDESCENT (5 of 5): Question

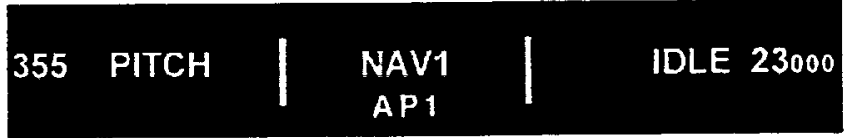

If you were to describe LATE DESCENT, Which of the following choices would you say it was most similar to?
A. PROF DESCENT
B. LEVEL CHANGE DESCENT
C. VERTICAL SPEED DESCENT
D. None of the above

Click on the correct Operational Procedure to continue.

LATE DESCENT (5 of 5): Question

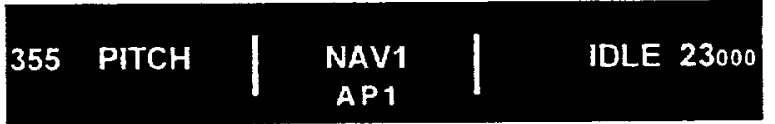

If you were to describe LATE DESCENT. Which of the following choices would you say it was most similar to?

\section{A. PROF DESCENT}

Sorry. PROF DESCENT refers to the aircraft maintaining the optimum descent path, similar to an ILS capture.

Try again. 
LATE DESCENT (5 of 5): Question

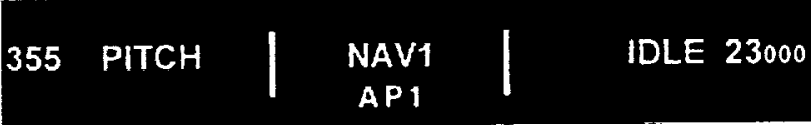

If you were to describe LATE DESCENT. Which of the following choices would you say it was most similar to?

\section{B. LEVEL CHANGE DESCENT}

Correct! In fact LATE DESCENT behaves exactly the same as a LEVEL CHANGE DESCENT in which the speed target is Vmo/Mmo - 10 knots.

LATE DESCENT (5 of 5): Question

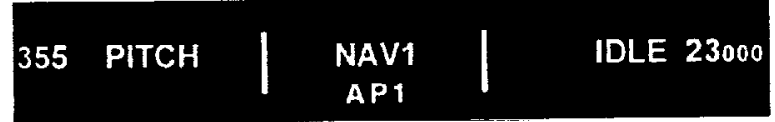

If you were to describe LATE DESCENT. Which of the following choices would you say it was most similar to?

\section{VERTICAL SPEED DESCENT}

Sorry. VERTICAL SPEED DESCENT refers to the aircraft controlling to a certain rate of descent, which is not what happens in LATE DESCENT. Try again. 
LATE DESCENT (5 of 5): Question

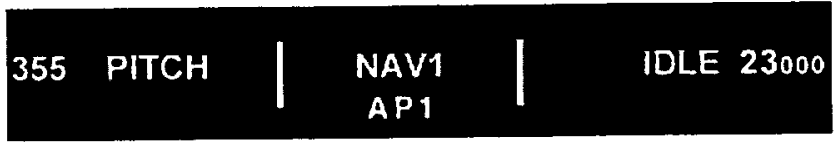

If you were to describe LATE DESCENT. Which of the following choices would you say it was most similar to?

D. None of the above

Sorry. There is a correct answer.

Try again. 


\section{APPENDIX D-EXPERIMENTAL PROCEDURE AND SIMULATED FLIGHT}

The following values were entered via the MCDU into the FMS:

In the INIT Page

KPDX/KSEA (KPDX is approx. N45.6, W122.62, Runway 10R)

Cost Index of 200 (FedEx) or 80 (Swiss Air)

Flight Number 0014

Final Cruise Altitude of FL330

Gross weight of 400,000 pounds

Fuel at 38,000 pounds per tank, tip tanks-full

TOCG (Take-Off Center of Gravity) 30.0

ZFWCG (Zero Fuel Weight Center of Gravity) 24.0

Flex of 50

In the Flight Plan Page

KPDX SID (standard instrument departure) of 10R

Add IMB (Kimberly) waypoint to the flight plan

Add CHINS2 arrival as a STAR (Standard Arrival)

Add AUBURN FMS Transition as a STAR

Add 16R as runway for Seattle

In the Takeoff/Approach Page

Air Temperature set to 15 degrees $C$

Winds set to 0 miles per hour $/ 0$ degrees direction

Confirm the V-Speeds 


\begin{tabular}{|c|c|c|}
\hline Situation & ATC Instruction & PNF Tasks \\
\hline $\begin{array}{l}\text { At Runway } \\
\text { threshold }\end{array}$ & $\begin{array}{l}\text { FDX } 14 \text { cleared to KSEA via Kimberly. Maintain } \\
5000 \text { feet, expect FL } 33010 \text { minutes after departure. } \\
\text { Maintain } 250 \text { knots until further advised. }\end{array}$ & $\begin{array}{l}\text { Set up FMS, perform after } \\
\text { start and below the line } \\
\text { checklists, set the flaps, set } \\
\text { the stabilizer and trim }\end{array}$ \\
\hline $\begin{array}{l}\text { At runway } \\
\text { threshold }\end{array}$ & FDX 14 cleared for Takeoff, runway heading & \\
\hline After check-in & FDX 14 , radar contact, climb and maintain 12,000 & Retract flaps and slats \\
\hline At $5000 \mathrm{ft}$ & FDX 14 turn left direct KIMBERLY when able & Perform Direct To function \\
\hline At $9500 \mathrm{ft}$ & FDX 14 climb and maintain FL 190 & \\
\hline $\begin{array}{l}\text { Above } \\
10,000 \mathrm{ft}\end{array}$ & & $\begin{array}{l}\text { Observe if } 250 \text { knot speed } \\
\text { restriction was followed }\end{array}$ \\
\hline At $10,500 \mathrm{ft}$ & FDX 14 resume normal speed & \\
\hline At $12,000 \mathrm{ft}$ & Stop 1 (Climb) & $\begin{array}{l}\text { Collect Question and FMA } \\
\text { data }\end{array}$ \\
\hline At $12,500 \mathrm{ft}$ & FDX 14 cleared direct CHINS when able & \\
\hline At $19,000 \mathrm{ft}$ & Stop 2 (Climb Intermediate Level) & $\begin{array}{l}\text { Collect Question and FMA } \\
\text { data }\end{array}$ \\
\hline At $19,500 \mathrm{ft}$ & $\begin{array}{l}\text { Climb and maintain FL310, this will be your final } \\
\text { altitude }\end{array}$ & \\
\hline At $26,000 \mathrm{ft}$ & Stop 3 (Climb) & $\begin{array}{l}\text { Collect Question and FMA } \\
\text { data }\end{array}$ \\
\hline At $31,000 \mathrm{ft}$ & Stop 4 (Cruise) & $\begin{array}{l}\text { Collect Question and FMA } \\
\text { data }\end{array}$ \\
\hline At $31,000 \mathrm{ft}$ & Stop 5 (Cruise) & $\begin{array}{l}\text { Collect Question and FMA } \\
\text { data }\end{array}$ \\
\hline $\begin{array}{l}\text { At } 31,000 \mathrm{ft} \\
\text { about } 35 \mathrm{mi} \\
\text { short of CHINS }\end{array}$ & $\begin{array}{l}\text { FDX 14, descend and maintain FL } 260 \text { (note: if pilot } \\
\text { asks if this is discretionary, say that it is not) }\end{array}$ & \\
\hline At $29,000 \mathrm{ft}$ & Stop 6 (Early Descent) & $\begin{array}{l}\text { Collect Question and FMA } \\
\text { data }\end{array}$ \\
\hline $\begin{array}{l}\text { At } 26,000 \mathrm{ft} \\
\text { and after } \\
\text { passing path }\end{array}$ & Stop 7 (Late Descent) & $\begin{array}{l}\text { Collect Question and FMA } \\
\text { data }\end{array}$ \\
\hline After Stop & FDX 14, descend and maintain FL 110 & \\
\hline $\begin{array}{l}\text { Approx } \\
16,000 \mathrm{ft} \\
\text { prior to } \\
\text { intercepting } \\
\text { the path }\end{array}$ & Stop 8 (Descent) & $\begin{array}{l}\text { Collect Question and FMA } \\
\text { data }\end{array}$ \\
\hline
\end{tabular}




\section{APPENDIX E-ANALYSIS OF VARIANCE (ANOVA) FOR EACH QUESTION ASKED DURING THE EXPERIMENT}

\section{FMA Template Data}

These data were collected at each of the eight stops. The data were scored as 1 for a correct score or 0 for an incorrect score. The mean values were calculated for each of the stops. A value of 1 in the table indicates that all participants got the question correct and there were no errors. A value of 0 in the table indicates that all participants got the question incorrect. The means of each condition are presented below for each of the three conditions.

One way ANOVAs were run on the questions that were recorded. Significance values are reported as either non-significant (ns) or with the associated $\mathrm{p}$-value. Significant differences are reported in Bold font to distinguish them from non-significant differences. All conditions had nine participants and there were no missing values.

The Whiz Wheel values for the G-FMA condition are repeated so they can be compared against the speed and altitude modes. If you will recall, the G-FMA had just a single mode response category where the participant built the G-FMA using the next operational procedure. The values are repeated so that accurate comparisons can be made between the three conditions.

$\begin{array}{lllll}\text { Stop 1 } & \text { Speed } & \text { Spd Mode } & \text { Pitch Mode } & \text { Altitude } \\ \text { G-FMA } & 1.0 & .67 & .67 & 1.0 \\ \text { Training } & 1.0 & .89 & 1.0 & 1.0 \\ \text { Baseline } & 1.0 & 1.0 & .89 & 1.0 \\ \text { significance } & \text { ns } & \text { ns } & \text { ns } & \text { ns }\end{array}$

$\begin{array}{lllll}\text { Stop 2 } & \text { Speed } & \text { Spd Mode } & \text { Pitch Mode } & \text { Altitude } \\ \text { G-FMA } & 1.0 & .89 & .89 & 1.0 \\ \text { Training } & 1.0 & .67 & .78 & 1.0 \\ \text { Baseline } & .89 & .56 & .67 & 1.0 \\ \text { significance } & \mathrm{ns} & \mathrm{ns} & \mathrm{ns} & \text { ns }\end{array}$




$\begin{array}{lllll}\text { Stop } 3 & \text { Speed } & \text { Spd Mode } & \text { Pitch Mode } & \text { Altitude } \\ \text { G-FMA } & 1.0 & 1.0 & 1.0 & 1.0 \\ \text { Training } & 1.0 & 1.0 & 1.0 & 1.0 \\ \text { Baseline } & 1.0 & .89 & .78 & 1.0 \\ \text { significance } & \text { ns } & \text { ns } & \text { ns } & \text { ns }\end{array}$

$\begin{array}{lllll}\text { Stop 4 } & \text { Speed } & \text { Spd Mode } & \text { Pitch Mode } & \text { Altitude } \\ \text { G-FMA } & 1.0 & \mathbf{. 8 9} & .89 & 1.0 \\ \text { Training } & 1.0 & \mathbf{. 6 7} & .68 & .68 \\ \text { Baseline } & 1.0 & .11 & .56 & .89 \\ \text { significance } & \text { ns } & .001 & \text { ns } & \text { ns }\end{array}$

$\begin{array}{lllll}\text { Stop 5 } & \text { Speed } & \text { Spd Mode } & \text { Pitch Mode } & \text { Altitude } \\ \text { G-FMA } & 1.0 & 1.0 & 1.0 & 1.0 \\ \text { Training } & 1.0 & .89 & .78 & .78 \\ \text { Baseline } & .89 & .78 & .78 & .89 \\ \text { significance } & \text { ns } & \text { ns } & \text { ns } & \text { ns }\end{array}$

$\begin{array}{lllll}\text { Stop 6 } & \text { Speed } & \text { Spd Mode } & \text { Pitch Mode } & \text { Altitude } \\ \text { G-FMA } & 1.0 & .89 & .89 & 1.0 \\ \text { Training } & 1.0 & .89 & 1.0 & 1.0 \\ \text { Baseline } & .89 & 1.0 & .89 & .78 \\ \text { significance } & \text { ns } & \text { ns } & \text { ns } & \text { ns }\end{array}$




$\begin{array}{lllll}\text { Stop } 7 & \text { Speed } & \text { Spd Mode } & \text { Pitch Mode } & \text { Altitude } \\ \text { G-FMA } & 1.0 & .78 & .78 & 1.0 \\ \text { Training } & .89 & .78 & .89 & .89 \\ \text { Baseline } & .78 & .67 & .78 & 1.0 \\ \text { significance } & \mathrm{ns} & \mathrm{ns} & \mathrm{ns} & \mathrm{ns} \\ & & & & \\ \text { Stop 8 } & \text { Speed } & \text { Spd Mode } & \text { Pitch Mode } & \text { Altitude } \\ \text { G-FMA } & .67 & .56 & .56 & 1.0 \\ \text { Training } & .78 & .33 & .44 & 1.0 \\ \text { Baseline } & .56 & .33 & .11 & 1.0 \\ \text { significance } & \mathrm{ns} & \mathrm{ns} & \mathrm{ns} & \mathrm{ns}\end{array}$

\section{Results for Flight Quizzes}

At each stop in the scenario (except for Stop 5), pilots were requested to fill out a set of three questions asking what was the speed target, what was the altitude target, and what was the behavior of the airplane. The first set of three questions was to apply to the current situation of the avionics (designated with an "a" below), and the second set was to apply to what the avionics would do next (designated with a "b" below). Questions were the same for all three conditions.

Each question was coded as a correct answer (value of 1.0) or incorrect (value of 0.0 ). A value of 1.0 in the table below indicates that all pilots in that condition got that question correct and there were no errors. The same reporting scheme is used as was done for the Whiz Wheel data above. 


\begin{tabular}{|c|c|c|c|}
\hline Stop Ia (Current) & Speed & Behavior & Altitude \\
\hline G-FMA & .89 & .89 & 1.0 \\
\hline Training & .78 & .67 & 1.0 \\
\hline Baseline & .78 & .67 & 1.0 \\
\hline significance & ns & ns & ns \\
\hline Stop $1 b$ (Next) & Speed & Behavior & Altitude \\
\hline G-FMA & .22 & .78 & 1.0 \\
\hline Training & .33 & .89 & .89 \\
\hline Baseline & .44 & .56 & .67 \\
\hline significance & ns & ns & ns \\
\hline Stop $2 a$ (Current) & Speed & Behavior & Altitude \\
\hline G-FMA & .89 & 1.0 & .89 \\
\hline Training & .56 & 1.0 & .89 \\
\hline Baseline & .56 & .56 & .89 \\
\hline significance & ns & .01 & ns \\
\hline Stop $2 b$ (Next) & Speed & Behavior & Altitude \\
\hline G-FMA & .89 & .63 & 1.0 \\
\hline Training & 1.0 & .56 & .89 \\
\hline Baseline & .68 & .33 & .67 \\
\hline significance & ns & ns & ns \\
\hline
\end{tabular}




$\begin{array}{llll}\text { Stop 3a (Current) } & \text { Speed } & \text { Behavior } & \text { Altitude } \\ \text { G-FMA } & 1.0 & 1.0 & 1.0 \\ \text { Training } & 1.0 & .56 & .78 \\ \text { Baseline } & 1.0 & .67 & .78 \\ \text { significance } & \mathrm{ns} & \mathrm{ns} & \mathrm{ns} \\ & & & \\ \text { Stop 3b (Next) } & \text { Speed } & \text { Behavior } & \text { Altitude } \\ \text { G-FMA } & 1.0 & 1.0 & 1.0 \\ \text { Training } & 1.0 & 1.0 & .89 \\ \text { Baseline } & .89 & 1.0 & 1.0 \\ \text { significance } & \mathrm{ns} & \mathrm{ns} & \mathrm{ns}\end{array}$

$\begin{array}{llll}\text { Stop 4a (Current) } & \text { Speed } & \text { Behavior } & \text { Altitude } \\ \text { G-FMA } & 1.0 & 1.0 & 1.0 \\ \text { Training } & .89 & 1.0 & 1.0 \\ \text { Baseline } & .89 & 1.0 & 1.0 \\ \text { significance } & \mathrm{ns} & \mathrm{ns} & \mathrm{ns}\end{array}$

$\begin{array}{llll}\text { Stop } 4 b \text { (Next) } & \text { Speed } & \text { Behavior } & \text { Altitude } \\ \text { G-FMA } & 1.0 & .78 & \mathbf{. 8 9} \\ \text { Training } & 1.0 & .89 & \mathbf{. 8 9} \\ \text { Baseline } & 1.0 & .89 & \mathbf{. 4 4} \\ \text { significance } & \text { ns } & \text { ns } & \mathbf{. 0 4}\end{array}$




$\begin{array}{llll}\text { Stop } 5 b(\text { Next }) & \text { Speed } & \text { Behavior } & \text { Altitude } \\ \text { G-FMA } & 1.0 & 1.0 & \mathbf{1 . 0} \\ \text { Training } & .89 & .78 & \mathbf{. 8 9} \\ \text { Baseline } & .78 & .78 & .56 \\ \text { significance } & \text { ns } & \text { ns } & .04\end{array}$

$\begin{array}{llll}\text { Stop 6a (Current) } & \text { Speed } & \text { Behavior } & \text { Altitude } \\ \text { G-FMA } & .89 & \mathbf{1 . 0} & 1.0 \\ \text { Training } & 1.0 & \mathbf{1 . 0} & 1.0 \\ \text { Baseline } & .78 & \mathbf{. 6 7} & .67 \\ \text { significance } & \mathrm{ns} & \mathbf{. 0 3} & \mathrm{ns}\end{array}$

$\begin{array}{llll}\text { Stop 6b (Next) } & \text { Speed } & \text { Behavior } & \text { Altitude } \\ \text { G-FMA } & \mathbf{. 6 3} & \mathbf{. 8 9} & .89 \\ \text { Training } & \mathbf{. 4 4} & \mathbf{1 . 0} & .89 \\ \text { Baseline } & \mathbf{. 1} & \mathbf{. 5 6} & .89 \\ \text { significance } & \mathbf{. 0 5} & \mathbf{. 0 3} & \mathrm{ns}\end{array}$

$\begin{array}{llll}\text { Stop 7a (Current) } & \text { Speed } & \text { Behavior } & \text { Altitude } \\ \text { G-FMA } & .78 & .89 & .89 \\ \text { Training } & .44 & .44 & .67 \\ \text { Baseline } & .68 & .56 & .67 \\ \text { significance } & \mathrm{ns} & \mathrm{ns} & \mathrm{ns}\end{array}$




$\begin{array}{llll}\text { Stop } 7 b \text { (Next) } & \text { Speed } & \text { Behavior } & \text { Altitude } \\ \text { G-FMA } & .67 & .78 & .89 \\ \text { Training } & .67 & .78 & .44 \\ \text { Baseline } & .11 & .56 & .56 \\ \text { significance } & .02 & \text { ns } & \text { ns } \\ & & & \\ \text { Stop 8a (Current) } & \text { Speed } & \text { Behavior } & \text { Altitude } \\ \text { G-FMA } & .44 & .89 & \mathbf{1 . 0} \\ \text { Training } & .78 & .89 & . \mathbf{5 6} \\ \text { Baseline } & .22 & .67 & \mathbf{. 8 9} \\ \text { significance } & \mathrm{ns} & \mathrm{ns} & \mathbf{. 0 4} \\ & & & \\ \text { Stop 8b (Next) } & \text { Speed } & \text { Behavior } & \text { Altitude } \\ \text { G-FMA } & .67 & .44 & \mathbf{1 . 0} \\ \text { Training } & .89 & .11 & \mathbf{. 5 6} \\ \text { Baseline } & .78 & .11 & \mathbf{. 3 3} \\ \text { significance } & \mathrm{ns} & \mathrm{ns} & \mathbf{. 0 1}\end{array}$




\section{APPENDIX F-RESULTS FROM THE SIMULATION EXPERIMENT}

\section{Training Ratings}

A questionnaire was given to pilots to get them to rate the characteristics of the tutor. Only pilots in the display and training conditions rated the tutor as these were the only groups that worked with this training program. There were no significant differences found between these two groups on each question. The data presented are the combined ratings of nine pilots from the display condition that saw the training and eight pilots from the training condition. In this second case, one of the pilots did not fill out a rating form for the tutor and this was not discovered until after the pilot had left the building and returned home. Numbers are presented in a frequency distribution for that question. For example, in the question on speed of presentation, two pilots felt that the presentation was too slow, while fifteen felt that the speed was about right.

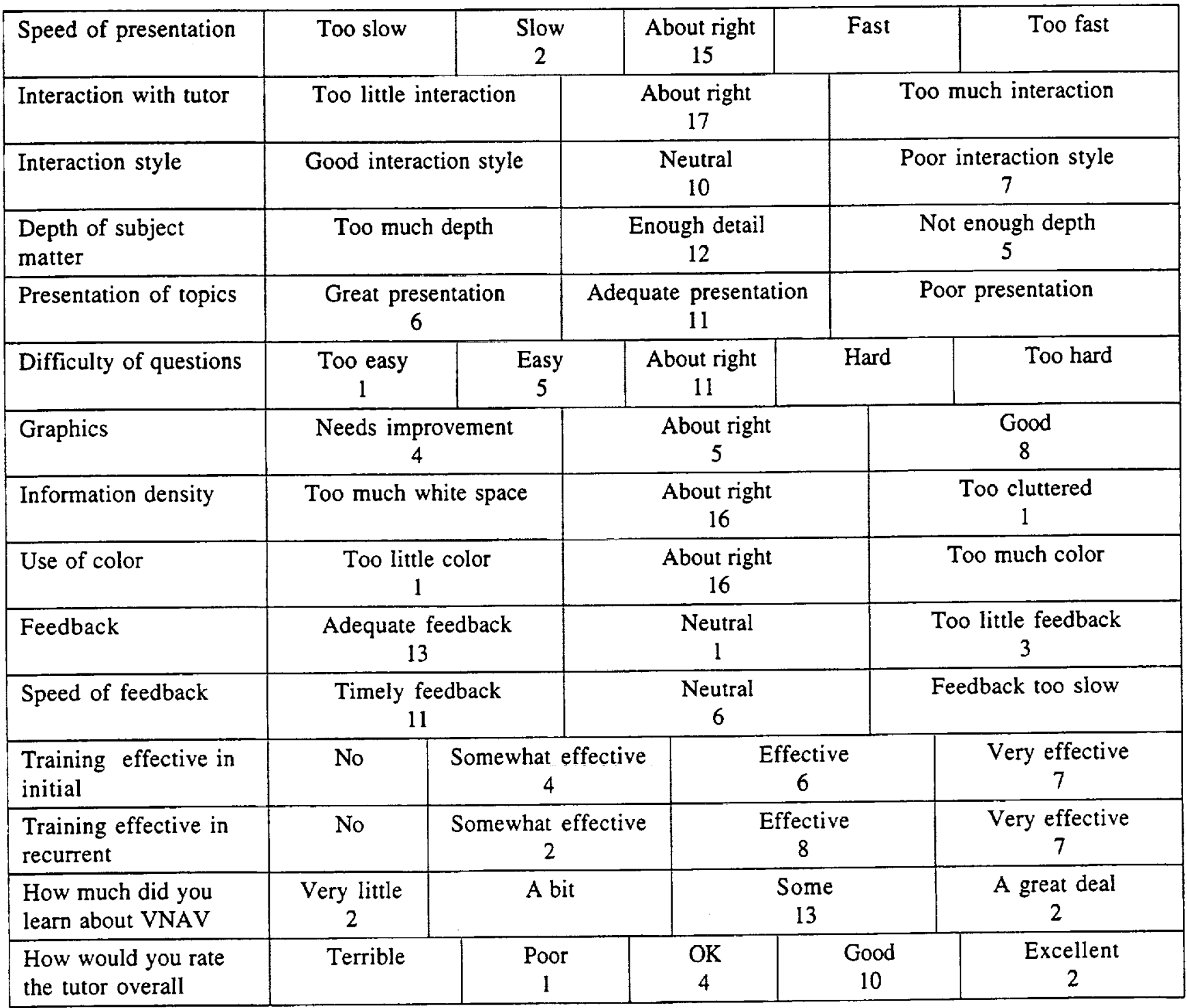




\section{Display Ratings}

We asked pilots to rate the G-FMA in comparison to the existing FMA on MD-11s on seven rating scales. For each question, a five-point scale was used and was coded as follows:

$\begin{array}{ll}\text { Strongly Agree } & 1 \\ \text { Agree } & 2 \\ \text { Neutral } & 3 \\ \text { Disagree } & 4 \\ \text { Strongly Disagree } & 5\end{array}$

The following were the questions that were given to the display group. For each question, the results are presented as the mean and standard deviation of each question using the rating scale above.

Mean

(Std Dev)

The G-FMA display provided me with information that was directly usable.

The G-FMA display was helpful in my understanding of what the plane was doing.

The G-FMA display helped me to understand the current mode of the 1.56 airplane.

I felt more confident in my understanding of the avionics with the G-FMA display.

I feel that the G-FMA display would help to minimize automation 1.89 surprises.

I used the Operational Procedure name to help me to understand what the avionics were doing.

I would like to see the new display on all Fed Ex MD-11s.

We also asked pilots to provide comments they had about the G-FMA. This was an open-ended question at the bottom of the questionnaire. The following comments were obtained from this inquiry. Each paragraph represents the complete comment that a pilot made about the new display.

Liked new FMA, but I am uncomfortable with removing thrust and pitch from the speed FMA. Speed on pitch can cause tailstrikes and this understanding is critical. Uncertain as to whether the new FMA will help or hinder this understanding.

G-FMA will be a useful tool/constant reminder of the AC position in relation to the FMS generated Vertical Flight Path. Along with the vertical path indicator, the words Early DES, Late DES are helpful indicator to this end. Display is good for Vertical Situation Awareness. 
Felt more confident in knowing what phase of flight the plane was in, not necessarily an understanding of the avionics. Incorporating some more speed information would be useful. Need speed on pitch/thrust combined with what phase of flight you are in.

Words used are not intuitive. Missed not having Pitch or Thrust available in speed FMA. Additional mode complexity may not enhance pilots ability to understand current mode.

Possibly different colors could be used for the unusual or different modes of vertical navigation, such as an alt constraint without having to look at the MCDU to verify.

\section{Simulation Comments}

Participants were asked in open-ended questions to rate the simulation and how well they thought the simulation approached normal flight. When asked how closely the simulation duplicated the reality of flying FedEx MD-11s, most of the pilots (21 of 27 , or $78 \%$ ) stated that the simulation was close. Two of the pilots indicated that we should do the study in a full-motion simulator, with one of those pilots stating that we should get a full FedEx crew for the flight and fly a more complete scenario. Two other pilots rated the simulation as "Fair," and one pilot stated that it was not a very close simulation and more emphasis on flight procedures was needed.

We also asked the pilots if there were any quirks in the displays or the way the simulator flew compared with the real airplane. Seventeen pilots stated that they did not see any differences (62\%). Three pilots commented on failures that were shown on the equipment acquisition document (EAD). This was due to our simulation and the fact that we were only running one FMC during the simulation. Three others commented on the differences in the FMAs; these pilots were in the display condition and were expected to see different FMA displays. We also had had two reports of simulation glitches, which may have been unique to the simulator.

A third question asked pilots if there was anything about the simulation that would influence the results of the study. Sixteen (59\%) of the participants said there wasn't anything that they felt would influence the study. Other comments that we received in this section were: need more climbs and descents, a two-man crew should be used, background talking was a distraction, and I should have been more prepared. These comments were individual comments that did not seem to fit the specific question that was asked.

\section{Next FMA Error Data}

At each stop, we asked pilots to build the next FMA that they would see (see figs. 7 and 8 for a pictorial of the FMA template that were used to collect these data). This was done to continually verify the pilot's understanding of what was coming up next. As pilots understand the avionics, they should be better able to tell us what the avionics will look like in the future. For the All column, all of the responses at each of the stops were added together for each participant. There was a significant difference with the G-FMA condition being significantly higher than the baseline group. This indicates that the G-FMA group got more of these responses correct than did respondents in the baseline group, 
hence they had a better understanding of the avionics. Examining the components that went into this overall score, however, did not identify any significant differences.

\begin{tabular}{|l|c|c|c|c|c|}
\hline \multicolumn{1}{|c|}{ Group } & All Stops & Speed & Spd Mode & Pitch Mode & Altitude \\
\hline Guid. FMA & $\mathbf{2 9 . 0 0}$ & 7.7 & 6.7 & 6.7 & 8.00 \\
\hline Training & $\mathbf{2 7 . 6 7}$ & 7.7 & 6.1 & 6.6 & 7.33 \\
\hline Baseline & $\mathbf{2 5 . 3 3}$ & 7.0 & 5.3 & 5.4 & 7.56 \\
\hline significance & $\mathbf{. 0 3}$ & ns & ns & ns & ns \\
\hline
\end{tabular}

Error data were also collected when pilots responded to the flight quiz. These data showed that there were significant differences between the groups for the composite index and for the behavior and altitude indices. There was a significant difference between the baseline and G-FMA groups for the All stops index, but neither the behavior nor the altitude indices had pairwise comparisons that were significant at the 0.05 level. These data support the notion that the understanding of the vertical guidance procedures was enhanced with the G-FMA and with the training groups. Both of these groups had higher scores which indicate that they got more correct in these categories.

\begin{tabular}{|l|c|c|c|c|}
\hline \multicolumn{1}{|c|}{ Group } & All Stops & Speed & Behavior & Altitude \\
\hline Guid. FMA & $\mathbf{3 9 . 2 2}$ & 12.00 & $\mathbf{1 2 . 7 8}$ & $\mathbf{1 4 . 4 4}$ \\
\hline Training & $\mathbf{3 5 . 4 4}$ & 11.67 & $\mathbf{1 1 . 5 7}$ & $\mathbf{1 2 . 2 2}$ \\
\hline Baseline & $\mathbf{3 0 . 2 2}$ & 9.67 & $\mathbf{9 . 5 6}$ & $\mathbf{1 1 . 0 0}$ \\
\hline significance & $\mathbf{. 0 1}$ & ns & $\mathbf{. 0 1}$ & $\mathbf{. 0 1}$ \\
\hline
\end{tabular}

Looking at the differences between the Current and Next stops proved interesting. The Current stops were those where we asked pilots to describe the current situation in terms of altitude target, speed target and airplane behavior. The Next stops asked pilots to describe those same concepts but off in the future. Looking at the summaries for the Current and Next stops, we found that the overall stop data were significant at both times. For the Current stops, the behavior that was mentioned was significantly different, with the G-FMA group being significantly different from the baseline group. Overall, the Current stops were different between the G-FMA and baseline groups as well. 
For the Next stop data, we found that, overall, the G-FMA condition was significantly different from both the baseline and training groups. The table below shows that, overall, there was a significant difference between the groups for all Current stops and all Next stops, indicating that understanding was greater for groups that had the display and training when compared to the baseline group. For the Current stops, it appears as if the behavior component was the significant contributor while the significant contributor for the Next stops was the altitude component. This indicates that the G-FMA group was better than the other two groups in stating what the behavior of the airplane was for the current situation, and they were better at pointing out the source of the altitude targets for the next situation.

\begin{tabular}{|l|c|l|l|l|l|l|l|l|}
\hline & \multicolumn{4}{|c|}{ Current Stops } & \multicolumn{5}{c|}{ Next Stops } \\
\hline \multicolumn{1}{|c|}{ Group } & All & Speed & Beh. & Alt. & All & Speed & Beh. & Alt. \\
\hline Guid. FMA & $\mathbf{1 9 . 2 2}$ & 5.89 & $\mathbf{6 . 6 7}$ & 6.67 & $\mathbf{2 0 . 0 0}$ & 6.11 & 6.22 & $\mathbf{7 . 6 7}$ \\
\hline Training & $\mathbf{1 6 . 8 9}$ & 5.44 & $\mathbf{5 . 5 6}$ & 5.89 & $\mathbf{1 8 . 5 6}$ & 6.22 & 6.00 & $\mathbf{6 . 3 3}$ \\
\hline Baseline & $\mathbf{1 5 . 5 6}$ & 4.89 & $\mathbf{4 . 7 8}$ & 5.89 & $\mathbf{1 4 . 6 7}$ & 4.78 & 4.78 & $\mathbf{5 . 1 1}$ \\
\hline significance & $\mathbf{. 0 1}$ & ns & $\mathbf{. 0 1}$ & ns & $\mathbf{. 0 1}$ & ns & ns & $\mathbf{. 0 1}$ \\
\hline
\end{tabular}




\section{APPENDIX G-DESCRIPTION OF THE INTENTIONAL FMA}

The annunciation for the automation of the vertical flight path management function should communicate the items listed in table G-1. The operational procedures, scenarios, behavior outputs, and behavior output functions may be annunciated on the FMA as illustrated in figure G-1. The scenario inputs can be annunciated on a vertical situation display (VSD).

Table G-1. Contents of Annunciation for Automated Vertical Flight Path Management

\begin{tabular}{|l|l|l|}
\hline \multicolumn{1}{|c|}{ Content } & \multicolumn{1}{|c|}{ OPM Element } & \multicolumn{1}{c|}{$\begin{array}{c}\text { Automation for Vertical Flight Path } \\
\text { Management }\end{array}$} \\
\hline Intention & Operational Procedure Name & VG Operational Procedure Name \\
\hline Reason for Intention & Scenario Name & Scenario Name \\
\hline Behavior & $\begin{array}{l}\text { Behavior Outputs and their } \\
\text { Functions }\end{array}$ & $\begin{array}{l}\text { Altitude Target - Function } \\
\text { Speed Target - Function } \\
\text { Vertical Speed Target - Function } \\
\text { Pitch/Thrust Control Mode - Function }\end{array}$ \\
\hline
\end{tabular}

\begin{tabular}{|c|c|c|}
\hline Next Speed Target & $\begin{array}{l}\text { Next Vertical Guidance } \\
\text { Operational Procedure }\end{array}$ & Next Altitude Target \\
\hline $\begin{array}{l}\text { Next Speed Target Behavior } \\
\text { Output Function }\end{array}$ & Next Pitch/Thrust Control Mode & $\begin{array}{r}\text { Next Altitude Target Behavior } \\
\text { Output Function }\end{array}$ \\
\hline Speed Target & $\begin{array}{c}\text { Vertical Guidance } \\
\text { Operational Procedure }\end{array}$ & Altitude Target \\
\hline $\begin{array}{l}\text { Speed Target Behavior } \\
\text { Output Function }\end{array}$ & $\begin{array}{c}\text { Pitch/Thrust Control } \\
\text { Mode } \\
\end{array}$ & $\begin{array}{r}\text { Altitude Target Behavior } \\
\text { Output Function } \\
\end{array}$ \\
\hline \multicolumn{3}{|c|}{ (a) Layout for Intentional-FMA } \\
\hline 260 & PATH DESCENT & 3000 \\
\hline Econ Descent CAS & PATH |IDLE-THRUST & Constraint at Approach Fix \\
\hline 280 & LATEDESCENT & 15000 \\
\hline $\begin{array}{l}\text { Econ Descent CAS + } 20 \\
\text { knots }\end{array}$ & SPEED | IDLE-THRUST & Clearance Altitude \\
\hline
\end{tabular}

(b) Example Intentional-FMA

Figure G-1. Example FMA for automated vertical flight path management. 


\section{REFERENCES}

Babbitt, B. A.; and Nystrom, C. O.: Training and Human Factors Research on Military Systems: Questionnaire Construction Manual. Fort Hood, TX: Army Research Institute for the Behavioral and Social Sciences (Tech Reports 89-20 and 89-21), 1989.

Billings, C. E.: Aviation Automation: The Search for a Human-Centered Approach. Mahwhad, NJ: Lawrence Erlbaum, 1997.

Crowther, E. G.; Chappell, A. R.; and Mitchell, C. M.: VNAV Tutor: System Knowledge Training for Improving Pilot's Mode Awareness. Paper presented at the 1994 IEEE International Conference on Systems, Man, and Cybernetics, San Antonio TX, Oct. 1994.

Eldredge, D.; Mangold, S.; and Dodd, R. S.: A Review and Discussion of Flight Management System Incidents Reported to the Aviation Safety Reporting System (Final report no. DOT/FAA/RD-92/2). Washington, DC: Battelle/U.S. Department of Transportation, 1992.

Endsley, M. R.: Measurement of Situation Awareness in Dynamic Systems. Human Factors, vol. 37, no. 1,1995 , pp. $65-84$.

Feary, M.: Control-Based vs. Guidance-Based Training and Displays for Automated Vertical Guidance. Unpublished master's thesis, San Jose, CA.: San Jose State University, 1997.

Feary, M.; Alkin, M.; Palmer, P.; Sherry, L.; McCrobie, D.; and Polson, P.: Behavior-Based vs. System-Based Training and Displays for Automated Vertical Guidance. In Proceedings of the Ninth International Symposium on Aviation Psychology, Columbus, OH, 1997.

Funk, K.; Lyall, B.; and Riley, V.: A Comprehensive Analysis of Flightdecks with Varying Levels of Automation (Phase 1 Final Report-Perceived Human Factors Problems of Flightdeck Automation). Eugene, OR: Oregon State University, 1995.

Hutchins, E.: Integrated Mode Management Interface Final Report. NASA Ames Research Center, 1996.

Hutchins, E.: Mode Management Made Simple. La Jolla, CA: University of California, San Diego, 1992.

Hutchins, E. L.; Hollan, J. D.; and Norman, D. A.: Direct Manipulation Interfaces. In D. A. Norman and S. W. Draper, eds., User Centered System Design. Hillsdale, N. J.: Erlbaum, 1986.

Mangold, S. J.; and Eldredge, D.: Flight Management Systems Information Requirements.

In R. S. Jensen, ed., Proceedings of the Eighth International Aviation Psychology Symposium Conference, Columbus: Ohio State University Press, 1995. 
McRuer, D.; Ashkenas, I.; and Graham, D.: Aircraft Dynamics and Control. Princeton, NJ: Princeton University Press, 1973.

Palmer, E.: “Oops, It Didn't Arm.” A Case Study of Two Automation Surprises. Paper presented at the 1995 Aviation Psychology Meeting, 1995.

Palmer, E.; Hutchins, E.; Ritter, R.; and vanCleemput, I.: Altitude Deviations: Breakdowns of an Error Tolerant System. NASA TM-108788, 1993.

Sarter, N.; and Woods, D.: Pilot Interaction with Cockpit Automation: Operational Experiences of the Flight Management System. International J. Aviation Psychology, vol. 2, no. 4, 1992, pp. 303-321.

Sherry, L.; Kelley, J.; McCrobie, D.; Polson, P. G.; Feary, M.; Hynes, C.S.; and Palmer, E.: Design of an Intentional Vertical Flight Path Management Function for the HSCT Cooperative Cockpit. Honeywell publication no. C69-5370-002, Phoenix, AZ, 1996.

Sherry, L.; and Polson, P. G.: Annunciation and Training of Knowledge-Based Avionics. Honeywell publication no. C69-5370-003, Phoenix, AZ, 1996.

Sherry, L.; Youssefi, D.; and Hynes, C. H.: A Formalism for the Specification of Operationally Embedded Reactive Avionics Systems. Honeywell publication no. C69-5350-001, Phoenix, AZ, 1995.

Spitzer, C. R.: Digital Avionics Systems. Englewood Cliffs, NJ: Prentice-Hall, 1987.

Vakil, S. S.; Hansman, R. J.; Midkiff, A. H.; and Vaneck, T.: Feedback Mechanisms to Improve Model Awareness in Advance Autoflight Systems. In Proceedings of the Eighth International Aviation Psychology Symposium, Columbus, OH: Ohio State University, 1995a.

Vakil, S. S.; Hansman, R. J.; Midkiff, A. H.; and Vaneck, T.: Mode Awareness in Advance Auto Flight Systems. Paper presented at the IFAC/IFIP/IFORS/IEA Symposium, Cambridge, MA, 1995b.

Wiener, E. L.: Human Factors of Advanced Technology ("Glass Cockpit”) Transport Aircraft. NASA CR-177528, 1989.

Woods, D. D.; Johannesen, L. J.; Cook, R. I.; and Sarter, N. B.: Behind Human Error: Cognitive Systems, Computers, and Hindsight. Wright Patterson AFB, Dayton, OH: CSERIAC, 1994. 
Public reporting burden for this collection of information is estimated to average 1 hour per response, including the time for reviewing instructions, searching existing data sources. gathering and maintaining the date needed, and completing and reviewing the collection of information. Send comments regarding this burden estimate or any other aspect of this Davis Highway, Suite 1204, Arlington, VA 22202-4302, and to the Office of Management and Budget, Paperwork Reduction Project (0704-0188), Washington, DC 20503. \begin{tabular}{|l|l|l}
\hline 1. AGENCY USE ONLY (Leave blank) & $\begin{array}{c}\text { 2. REPORT DATE } \\
\text { February } 1998\end{array}$ & $\begin{array}{c}\text { 3. REPORT TYPE AND DATES COVERED } \\
\text { Technical Memorandum }\end{array}$
\end{tabular} February 1998

\section{TITLE AND SUBTITLE}

Aiding Vertical Guidance Understanding

6. AUTHOR(S)

Michael Feary, ${ }^{*}$ Daniel McCrobie, ${ }^{\dagger}$ Martin Alkin, ${ }^{\dagger}$ Lance Sherry, ${ }^{\dagger}$

Peter Polson, ${ }^{\S}$ Everett Palmer, and Noreen McQuinn"

7. PERFORMING ORGANIZATION NAME(S) AND ADDRESS(ES)

Ames Research Center

Moffett Field, CA 94035-1000

9. SPONSORING/MONITORING AGENCY NAME(S) AND ADDRESS(ES)

National Aeronautics and Space Administration

Washington, DC 20546-0001
5. FUNDING NUMBERS

$548-40-12$

8. PERFORMING ORGANIZATION

REPORT NUMBER

A-98-09160

10. SPONSORING/MONITORING AGENCY REPORT NUMBER

NASATM-1998-112217

11. SUPPLEMENTARY NOTES

Point of Contact: Michael Feary, Ames Research Center, MS 262-4, Moffett Field, CA94035-1000; (650) 604-0203

*San Jose State Univ., San Jose, CA 'Honeywell Inc., Phoenix, AZ 'FFederal Express Inc., Memphis, TN

${ }^{\S}$ Univ. of Colorado, Boulder, CO "Boeing-Douglas Products Division, Long Beach, CA

12a. DISTRIBUTIONIAVAILABILITY STATEMENT

12b. DISTRIBUTION CODE

Unclassified - Unlimited

Subject Category 06

\section{ABSTRACT (Maximum 200 words)}

A two-part study was conducted to evaluate modern flight deck automation and interfaces. In the first part, a survey was performed to validate the existence of automation surprises with current pilots. Results indicated that pilots were often surprised by the behavior of the automation. There were several surprises that were reported more frequently than others. An experimental study was then performed to evaluate (1) the reduction of automation surprises through training specifically for the vertical guidance logic, and (2) a new display that describes the flight guidance in terms of aircraft behaviors instead of control modes. The study was performed in a simulator that was used to run a complete flight with actual airline pilots. Three groups were used to evaluate the guidance display and training. In the training condition, participants went through a training program for vertical guidance before flying the simulation. In the display condition, participants ran through the same training program and then flew the experimental scenario with the new GuidanceFlight Mode Annunciator (G-FMA). Results showed improved pilot performance when given training specifically for the vertical guidance logic and greater improvements when given the training and the new G-FMA. Using actual behavior of the avionics to design pilot training and FMA is feasible, and when the automated vertical guidance mode of the Flight Management System is engaged, the display of the guidance mode and targets yields improved pilot performance.

14. SUBJECT TERMS

Automation, Flight Management System, Vertical guidance

15. NUMBER OF PAGES 85

16. PRICE CODE A05

\begin{tabular}{l|l}
\hline 17. SECURITY CLASSIFICATION & 18. SECURITY CLASSIFICATION \\
OF REPORT & OF THIS PAGE \\
Unclassified & Unclassified \\
\hline
\end{tabular}

19. SECURITY CLASSIFICATION OF ABSTRACT 